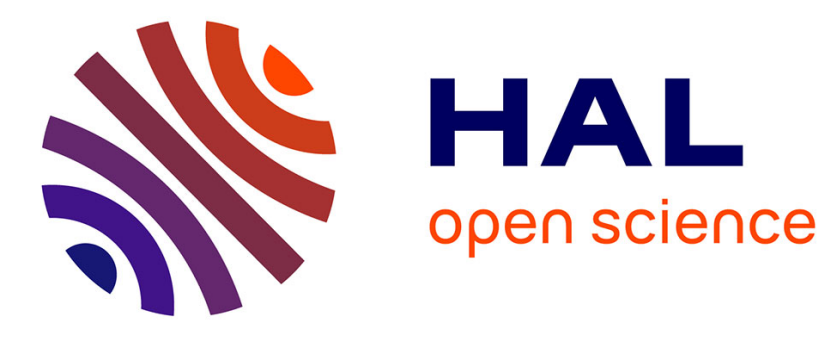

\title{
A three-level approach to the semantics of space
}

\author{
Michel Aurnague, Laure Vieu
}

\section{To cite this version:}

Michel Aurnague, Laure Vieu. A three-level approach to the semantics of space. Cornelia ZelinskyWibbelt. The semantics of prepositions: from mental processing to natural language processing, 3 (chapter 4. Image understanding and prepositions), Mouton de Gruyter, pp.393-439, 1993, Natural Language Processing, 978-3110136340. 10.1515/9783110872576.393 . hal-00462578

\section{HAL Id: hal-00462578 https://hal.science/hal-00462578}

Submitted on 10 Mar 2010

HAL is a multi-disciplinary open access archive for the deposit and dissemination of scientific research documents, whether they are published or not. The documents may come from teaching and research institutions in France or abroad, or from public or private research centers.
L'archive ouverte pluridisciplinaire HAL, est destinée au dépôt et à la diffusion de documents scientifiques de niveau recherche, publiés ou non, émanant des établissements d'enseignement et de recherche français ou étrangers, des laboratoires publics ou privés. 


\title{
A THREE-LEVEL APPROACH TO THE SEMANTICS OF SPACE
}

\author{
Michel Aurnague*, Laure Vieu** \\ IRIT 118, route de Narbonne 31062 Toulouse cedex France \\ tel.: (33) 61556764 - fax: (33) 61556258
}

\section{Introduction}

The aim of our work is to elaborate some formal tools in order to represent the semantic content of Natural Language (henceforth NL) expressions referring to space, in the framework of French text analysis. Many NL markers allow us to describe space but, usually, it is possible to classify them in two main groups: spatial referents (nouns and adjectives), and spatial relations (prepositions, verbs of movement). We give some examples below:
(1) referents
a. Le haut de la tour est en ruine 'The top of the tower is in ruins'
b. L'arbre est haut de 5 mètres
'The tree is 5 meters high'
(2) relations
a. Le restaurant est situé entre la banque et le bureau de poste
'The restaurant is situated between the bank and the post office'
b. Le bateau s'éloigne de la côte
'The boat is going away from the coast'

It can be observed that whereas referents (sentences (1a) and (1b)) identify a portion of an object, relations (sentences (2a) and $2 b$ )) situate a

\footnotetext{
* At present in Equipe Recherches en Syntaxe et Sémantique, URA 1033 (CNRS), Université Toulouse-Le Mirail \& Equipe Langue, Raisonnement, Calcul, IRIT.email: aurnague@irit.fr

** Present address: Laboratoire d'Intelligence Artificielle, INRA, chemin de Borde-Rouge, 31326 Castanet-Tolosan cedex, France. tel: (33) 612852 85, fax: (33) 2852 80, email: vieu@toulouse.inra.fr
} 
localized object (called trajector) with respect to a reference object (called landmark). We take as source data discourses containing sentences like those above and try to represent their semantic content with the formal tools we build.

The elaboration of these representations follows a methodology based on two main points. First, the study is based on a detailed and systematic linguistic analysis which must highlight and classify the different meanings of each lexeme, in particular (in the field of spatial expressions) the distinct spatial configurations it refers to. This survey of the different meanings has to be as detailed and systematic as possible so as to formalize the semantics of the spatial expressions covering all their possible uses. Since we are interested in the expression of space in NL, we naturally set aside all the uses of the lexemes studied which are not purely spatial or not about concrete objects like, for instance, metaphorical uses. The second point of our methodology concerns the elaborated formalisms which, beyond the representation of the semantic content, should have adequate inferential properties. This means that we want to use the formalisms to make deductions whose results must be similar to the reasoning made by a human being. We consider that a "complete" semantics must aim not only at encoding the content of the lexemes studied, but also at reproducing the human reasoning involving those lexemes. Moreover, such a comparison between the results of inferences and reasoning constitutes a real way to validate the semantics elaborated. A direct consequence of this inferential constraint is the choice of first-order logic as an appropriate framework to build our formal tools.

The representation system of spatial entities and relations whose main lines we explain here has been used to give a formal definition to the prepositions dans 'in' and sur 'on' and to some Internal Localization Nouns (henceforth ILN) such as haut 'top', bas 'bottom', devant 'front extremity', dessus 'top extremity', intérieur 'inside', bord 'edge', angle 'corner', etc., which are all lexical elements pointing out the different portions of an object (Borillo, A. 1988). The two prepositions sur 'on' and dans 'in' and the ILNs have been studied in the following syntactic structure which corresponds to a static localization process: 
Ntraj être prep [ILN de] Nland

'Ntraj to be prep [ILN of] Nland'

Some examples of sentences constructed according to this structure are

(3) a. Les armoiries sont sur le devant de la maison

'The coat of arms is on the front (extremity) of the house'

b. Le livre est dans l'armoire

'The book is in the cupboard'

In this paper we look closely into the semantics of sur 'on' and dans 'in' showing that a three-level approach (geometrical, functional, pragmatic) enables us to appropriately formalize their spatial uses.

\section{An analysis on three levels}

Throughout this paper, we try to illustrate our approach to the semantic analysis of spatial expressions, namely that we advocate distinguishing between several types of elements which make up their meaning.

There are two main reasons for this. First of all, these elements clearly belong to different qualitative categories: separate treatment is therefore more efficient. Second, studying what is going on within each category and between them forces us to go deeper into the analysis of the semantics at stake than if we adopt a global approach. As a result, we progress towards one of the principal goals of our work, that is, obtaining adequacy between the inferences which can be drawn from the representation system and the deductions acknowledged by common sense.

The observation on which the first reason is based is founded to a large extent on the linguistic analysis of the spatial prepositions in two important works: (Herskovits 1982) and (Vandeloise 1986). Nonetheless, we should note that their authors do not conclude as we do and stick mainly to a global approach.

\subsection{Definition of the three levels}

Contrary to (Leech 1969) and to a certain extent (Miller - Johnson-Laird 1976), Vandeloise showed in (Vandeloise 1986) that a purely geometrical representation of the semantics of spatial prepositions is not appropriate. For 
instance, if sur 'on' were represented only with the relation of contact, we could not make the difference between the sentences (4a) and (4b):

(4) a. L'affiche est sur le mur

'The poster is on the wall'

b. L'armoire est contre le mur

'The cupboard is against the wall'

In the same way, if the inclusion of the trajector in the convex hull of the landmark fully described the preposition dans 'in' (which is described this way or simply by inclusion in most of the literature), we would not explain why in the situation depicted by Figure 1, sentence (5) cannot be asserted (this last example is taken from (Herskovits 1982)).

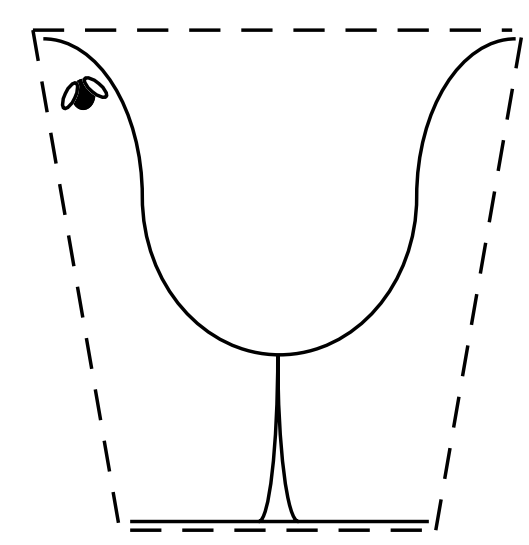

Figure 1

\section{La mouche est dans le verre}

'The fly is in the glass'

In these examples, the geometrical approach does not take into account the functional components of the semantics of the prepositions sur 'on' and dans 'in': for the first one, the notion of support is essential, and for the second, containment is very important. More generally, the functional aspects of the relations and entities they describe play a major part in the semantics of spatial markers. These functional aspects may belong to the "naive physics group" (as defined in (Hayes 1985)), as do the relations of support and containment; or they may belong to the "orientation group", as do the functionality of a cupboard which makes it possible to speak of the front part 
of the cupboard; finally, they may belong to the "structure group", as do the characteristic of being considered as discrete or continuous and all the aspects concerning the composition of the entities.

As in any field of NL, pragmatic phenomena influence the semantics of the spatial markers, as can be seen in the following example.

\section{(6) a. La voiture est dans le garage}

'The car is in the garage'

b. Le moteur de la voiture est dans le garage

'The car's engine is in the garage'

c. Le moteur de la voiture n'est pas dans le garage

'The car's engine is not in the garage'

From sentence (6a) the semantics of dans 'in' should enable us to infer sentence (6b). Indeed, if (6a) is true, then (6b) is also true or at least it cannot be denied: clearly, here (6c) is false. Nevertheless, knowing (6a), we would not utter (6b) alone because it somehow "implies" that the engine is separated from the car, lying somewhere in the garage.

Several pragmatic principles can be isolated, as for instance the "principle of maximum trajector" involved in the last example: "do not localize a part if you can localize the whole, unless you have good reasons to do so" and its corollary "generally, the entity localized is not a part of a bigger entity being in the same situation". These principles or conventions are in fact instances of more general ones that rule any kind of discourse or dialogue, as Grice's cooperative principle which is composed of four maxims (Grice 1975) (the principle of maximum trajector is just a particular case of the maxim of quantity), and the search for the highest degree of typicality. Of course, these principles generate implicatures (as the above corollary), not inferences. Consequently, these will have to be represented within a nonmonotonic logic. We should also stress that they need more information than is contained in the text being analysed, that is, they often rely on world knowledge (here we used the knowledge that a car has an engine) and extralinguistic context (here we have assumed a "normal" context, not one, for instance, in which the car engine has just exploded and someone is asking where it occurred). 
To sum up, we have identified three types of elements involved in the "meaning" of the spatial markers we studied. First, there are of course the geometrical properties of the entities and the geometrical relations, which cannot be put aside. ${ }^{1}$ Second, we have seen that the functional properties and relations also play an important part. Third, we have seen that pragmatic principles together with a representation of (some) world knowledge and (part of) the context can significantly modify what is obtained from the elements of the first two types only. Consequently, the representation system we have built to formalize the semantics of the spatial markers consists of three parts.

\subsection{Organization of the levels}

Before we start looking into each one of the three parts which make up the representation system, we must say a word on how these parts are organized.

The geometrical level is at the root of this system. It constitutes a formal structure where we represent the objective, purely spatial data present in the text analysed. This data is said to be objective not only because it does not take into account context and discourse conventions, but also because it is independent from the function and internal structure of the entities, which is often induced by the particular point of view the speaker has chosen when naming the entities. For instance, sentences (7a) and (7b) describe the same geometrical relation (contact and relative position on the vertical axis) between the same concrete "objects", although the two entities they localize are different, for the first may be new while the second may be old.

\section{(7) a La bague est sur la table \\ 'The ring is on the table' \\ b Le morceau d'or est sur la table}

'The piece of gold is on the table'

This difference is not taken into account on the geometrical level, but on the functional level where all the properties of the entities are represented. As a consequence, and to emphasize the difference between these two levels, we look upon the elements handled on the geometrical level as different from the entities handled on the functional level: we call them the "spatial referents" of the entities. Formally, it is just a trick to say that all the entities describing the 
same concrete object, and thus the same "space portion", make up an equivalence class with respect to the geometrical relations.

The functional level is of course based on the geometrical level, since the spatial properties are part of the properties of the entities, and many functional relations imply geometrical ones (e.g. containment implies inclusion in the interior). It is at this level that we represent the "crude" semantics of the spatial markers we have studied. Here and on the geometrical level, all the information, including the inferred information, is certain; that is, this information is not defeasible, although some pragmatic principles may act later as a filter and eliminate "what is not false but cannot be said" when using the system in a generation mode (for instance, answering a question).

The pragmatic level relies heavily on functional properties as will be seen in the fifth section. In addition, it needs two different structures to represent context and world knowledge, but these will not be dealt with in this paper, as much work remains to be done on them. The specific knowledge that the pragmatic level embodies is procedural: either it works as a filter as we just mentioned, or it produces defeasible information. It is also here that an occurrence of a spatial expression is interpreted as an instance of a particular case $^{2}$ of this expression. These processes are not completely formalized at the moment, so in section 5 we will simply present in an informal way what in the meaning of the studied spatial markers we feel belongs to this level, and we will try to justify it. Even though we know that the separation between semantics and pragmatics is highly controversial, we feel we could use the term semantics to designate the first two levels and the term pragmatics for the third. We hope the reader is kind enough not to take offence at this, in case s/he uses these two terms in a different manner.

\section{The geometrical level}

As it has been underlined, on the geometrical level we handle the spatial referents of the entities, that is the space portion determined by their matter at a given time. At this level we deal with the topological notions of inclusion, contact, boundary, etc., and with concepts related to projective geometry such as straight line, distance, order on a straight line, etc. 
The actual use of prepositions like sur 'on' and dans 'in' which allows us to situate a trajector with respect to a landmark shows the relational nature of the structures handled in the language as opposed to the absolute spaces used in robotics (where entities are localized by means of coordinates). This property of space in NL has also been emphasized in various works related to psychology and linguistics like those of G. Miller \& P. Johnson-Laird (Miller - Johnson-Laird 1976), L. Talmy (Talmy 1983), A. Herskovits (Herskovits 1982) or C. Vandeloise (Vandeloise 1986). In addition, researchers like P. Hayes (Hayes 1976) who, in the field of naive physics, try to formalize commonsense reasoning, make a similar assumption. Moreover, two properties of these absolute spaces seem to contradict the structures of space in NL. Whereas, in a coordinate system, the positions of every entity need to be known exactly, the spatial information expressed in a text is often partial and imprecise. Another problem arises from the fact that the variable granularity of space in NL (for instance in NL the same entity can be considered at one time as a point and later as a volume) is not compatible with the discrete structure characterizing an implementable coordinate system, where the minimum units are defined a priori. So, knowledge representation on the geometrical level will be done within a relational structure and not within a coordinate system. As a consequence, the spatial referent of the entities will be taken as primitive elements and not, for instance, as sets of points of an Euclidean space. Space is therefore built from the text and not assumed beforehand (this is similar to the construction of time proposed in (Kamp 1979)).

It must be stressed that, contrary to an absolute space in which all geometrical concepts can be expressed by using classical theories of mathematics (for instance, Euclidean geometry), relational structures imply formalizing topology and projective geometry in two independent modules. We already showed in (Aurnague 1991) and (Vieu 1991) that, up to now, every attempt to express those two data types within only one qualitative formalism has failed. Consequently, the geometrical level of the system is made up of two distinct modules, one dealing with topological information and the other with projective geometry. 


\subsection{Topology}

In order to fulfil the relational requirement mentioned above, we formalize the topological information using the individual calculus based on connection proposed by B.L. Clarke (Clarke 1981) (Clarke 1985). In fact, we use an extended version of this theory because we modified and completed it so as to take into account some important spatial concepts in language. Following this work and the mereological ${ }^{3}$ tradition derived from (Leonard - Goodman 1940), we call the spatial referents of the entities "individuals". This calculus is based on the sole relation of connection between two individuals (noted $\mathrm{c}(\mathrm{X}, \mathrm{Y}))$ to which B.L. Clarke does not give any precise interpretation. However, in order to provide help in reading the axioms, definitions and theorems, B.L. Clarke suggests (according to A.N. Whitehead) considering variables as spatiotemporal individuals, which is the case in our use of this theory, and stating that two individuals are connected if they "share at least one point" (which has no real meaning here since we do not interpret the spatial referents as sets of points). This primitive connection is used to define some mereological operators as well as Boolean and topological ones. It is characterized by two axioms, the first stating reflexivity and symmetry and the latter being a kind of "axiom of extension" based on a second primitive, the identity relation $=_{\mathrm{s}}$ :

- $\forall \mathrm{X} c(\mathrm{X}, \mathrm{X}) \wedge \forall \mathrm{X} \forall \mathrm{Y}(\mathrm{c}(\mathrm{X}, \mathrm{Y}) \Rightarrow \mathrm{c}(\mathrm{Y}, \mathrm{X}))$

- $\forall \mathrm{X} \forall \mathrm{Y}\left(\forall \mathrm{Z}(\mathrm{c}(\mathrm{Z}, \mathrm{X}) \Leftrightarrow \mathrm{c}(\mathrm{Z}, \mathrm{Y})) \Rightarrow \mathrm{X}={ }_{\mathrm{s}} \mathrm{Y}\right)$.

As regards mereology, the disconnection $(\mathrm{X}$ is disconnected from $\mathrm{Y}$ : $\mathrm{dc}(\mathrm{X}, \mathrm{Y})$ ) between two individuals and the configurations of inclusion $(\mathrm{X}$ is included in $\mathrm{Y}: \mathrm{p}(\mathrm{X}, \mathrm{Y})$ ) and overlapping (X overlaps $\mathrm{Y}: \mathrm{o}(\mathrm{X}, \mathrm{Y})$ ) are introduced. The inclusion, for instance, is defined stating that $\mathrm{X}$ is included in $\mathrm{Y}$ if every $\mathrm{Z}$ connected with $\mathrm{X}$ is also connected with $\mathrm{Y}$ :

$$
\mathrm{p}(\mathrm{X}, \mathrm{Y}) \equiv_{\mathrm{def}} \forall \mathrm{Z}(\mathrm{c}(\mathrm{Z}, \mathrm{X}) \Rightarrow \mathrm{c}(\mathrm{Z}, \mathrm{Y}))
$$

Then, the notion of a proper part (strict inclusion) $\mathrm{X}$ of an individual $\mathrm{Y}$ can be expressed as:

$$
\mathrm{pp}(\mathrm{X}, \mathrm{Y}) \equiv_{\operatorname{def}} \mathrm{p}(\mathrm{X}, \mathrm{Y}) \wedge \neg \mathrm{p}(\mathrm{Y}, \mathrm{X})
$$

It must be noted that the part-whole relations (also called meronomies) used in the language (e.g.: cette roue est une partie de ma voiture, 'this wheel is a part of my car') are much more complex than the mere geometrical inclusion because they involve many functional factors depending directly on 
the entity (and not only on its spatial referent). Consequently, we define this type of relation on the functional level of the system.

Two individuals $\mathrm{X}$ and $\mathrm{Y}$ are overlapping each other if they share a common individual $\mathrm{Z}$ :

$$
\mathrm{o}(\mathrm{X}, \mathrm{Y}) \equiv_{\operatorname{def}} \exists \mathrm{Z}(\mathrm{p}(\mathrm{Z}, \mathrm{X}) \wedge \mathrm{p}(\mathrm{Z}, \mathrm{Y}))
$$

Bringing something new to classical mereology (Lesniewski 19271931) (Leonard - Goodman 1940), the distinction between connection and overlapping allows B.L. Clarke to define the situation in which two elements are externally connected:

$$
\mathrm{ec}(\mathrm{X}, \mathrm{Y}) \equiv_{\operatorname{def}} \mathrm{c}(\mathrm{X}, \mathrm{Y}) \wedge \neg \mathrm{O}(\mathrm{X}, \mathrm{Y})
$$

A portion $\mathrm{X}$ of an individual $\mathrm{Y}$ is called a tangential part of $\mathrm{Y}$ if there exists an individual $\mathrm{Z}$ externally connected to both $\mathrm{X}$ and $\mathrm{Y}$ (the notion of non-tangential part is defined in the same way).

In the Boolean part of the calculus, the operators sum (+), product (prod) and complement (-) are defined. We assume here and in the following that the reader is familiar with lattice structures and Boolean algebra. This part of the theory is called pseudo-Boolean because of the lack of a null element which follows from a philosophical postulate of S. Lesniewski (Lesniewski 1927-1931) taken up by A. N. Whitehead (Whitehead 1929) and B.L. Clarke. According to this postulate, all the individuals handled in the calculus must have a concrete existence, which is not the case of the null element.

The third, and last, part of this calculus covers the topological aspects themselves; it consists in defining the interior of an individual, its closure as well as the properties of being closed and open. With this aim, B.L. Clarke introduces the fusion operator $\mathrm{f}$ between an individual $\mathrm{X}$ and a set of individuals $\alpha$ stating that $\mathrm{X}$ constitutes the fusion of $\alpha$ if, for every $\mathrm{Y}$ connected to $\mathrm{X}$, there exists an element $\mathrm{Z}$ of $\alpha$ which is also connected to $\mathrm{Y}$ :

$$
\mathrm{X}=\mathrm{f}(\alpha) \equiv_{\text {def }} \forall \mathrm{Y}(\mathrm{c}(\mathrm{Y}, \mathrm{X}) \Leftrightarrow \exists \mathrm{Z}(\mathrm{Z} \in \alpha \wedge \mathrm{c}(\mathrm{Y}, \mathrm{Z}))) \text {. }
$$

Furthermore, an axiom ensures, for any set $\alpha$, the existence of an individual $\mathrm{X}$ corresponding to its fusion ( $\Lambda$ being the empty set):

$\forall \alpha(\neg(\alpha=\Lambda) \Rightarrow \exists \mathrm{X} X=\mathrm{f}(\alpha))$.

Then the interior of an individual $\mathrm{X}$ can be defined as the fusion of its non-tangential parts:

$$
\mathrm{i}(\mathrm{x}) \equiv_{\operatorname{def}} \mathrm{f}(\{\mathrm{Y}: \mathrm{NTP}(\mathrm{Y}, \mathrm{X})\}) .
$$


The closure of $\mathrm{X}$ is calculated by fusing all the individuals which are not connected to the interior of its complement:

$$
\mathrm{c}(\mathrm{x}) \equiv_{\operatorname{def}} \mathrm{f}(\{\mathrm{Y}: \neg \mathrm{c}(\mathrm{Y}, \mathrm{i}(-(\mathrm{X})))\})^{4} \text {. }
$$

Here too it must be underlined that the topological interior of an individual does not correspond to what we usually call interior in the language. For example, when people refer to the natural interior of the glass, they are usually pointing out the portion of space enclosed between its sides (where one can put water) and not to the very interior of those sides which contains only glass and actually corresponds to the topological interior. As the functional aspects play a great part in determining the natural interior of an entity, we introduce this notion on the functional level of the system.

From the topological operators "interior" and "closure", open and closed individuals can be characterized in the following way:

- $\mathrm{op}(\mathrm{X}) \equiv_{\mathrm{def}} \mathrm{X}=\mathrm{i}(\mathrm{X})$

- $\operatorname{cl}(\mathrm{X}) \equiv_{\mathrm{def}} \mathrm{X}=\mathrm{c}(\mathrm{X})$

This topological part of the calculus is called pseudo because of the impossibility of handling boundary elements present in classical topology. The principal reasons behind this are the lack of a null element and the distinction between external connection and overlap configurations.

Finally, B.L. Clarke introduces an axiom which states that every individual has an interior (i.e. it has a non-tangential part) and constrains the product between two open elements to be itself open:

$$
\begin{aligned}
& \forall \mathrm{X}[\exists \mathrm{Z} \operatorname{ntp}(\mathrm{Z}, \mathrm{X}) \wedge \forall \mathrm{Y}[\forall \mathrm{Z}[(\mathrm{c}(\mathrm{Z}, \mathrm{X}) \Rightarrow \mathrm{o}(\mathrm{Z}, \mathrm{X})) \wedge \\
& (\mathrm{c}(\mathrm{Z}, \mathrm{Y}) \Rightarrow \mathrm{o}(\mathrm{Z}, \mathrm{Y}))] \Rightarrow \forall \mathrm{Z}[\mathrm{c}(\mathrm{Z}, \operatorname{prod}(\mathrm{X}, \mathrm{Y})) \Rightarrow \mathrm{o}(\mathrm{Z}, \operatorname{prod}(\mathrm{X}, \mathrm{Y}))]]] .
\end{aligned}
$$

The individual calculus based on connection, whose main lines we have just set out, is not sufficient as it is to deal with problems related to the semantics of space in language. Consequently, we have extended this theory in order to express some fundamental spatial notions in the language, such as limit, contact, etc.

We noted that one of the main spatial concepts handled in language, limit, could not be directly taken into account by B.L. Clarke's calculus. In order to make up for this lack, we introduce the notion of empty individual and regard a limit as a tangential part having an empty interior. The principal reason why limits can be considered as individuals comes from the fact that we work in a finite domain. If we had added a non-atomicity condition, it would not have been possible to define them in this way since they would 
have corresponded to the classical notion of limit in mathematics. Moreover, we can characterize the limits in terms of empty individuals because the spatial referents of the objects we handle are closed and not open. An individual is empty if each of its portions are open:

$$
\operatorname{vide}(\mathrm{X}) \equiv_{\text {def }} \forall \mathrm{Y}[\mathrm{p}(\mathrm{Y}, \mathrm{X}) \Rightarrow \mathrm{op}(\mathrm{Y})] \text {. }
$$

Using this property, we build three types of limits $(\lim 1, \lim 2, \lim 3)$ through which surfaces, lines and points can be differentiated.

A portion $\mathrm{X}$ of $\mathrm{Y}$ is a limit1 if it is a tangential part of $\mathrm{Y}$ having an empty interior and if any tangential part of $\mathrm{X}$ is also a tangential part of $\mathrm{Y}$ (which means that everything inside the limit is flush with it):

$\lim 1(X, Y) \equiv_{\text {def }} \operatorname{vide}(\mathrm{i}(X)) \wedge \operatorname{tp}(X, Y) \wedge \forall Z[\operatorname{tp}(Z, X) \Rightarrow \operatorname{tp}(Z, Y)]$.

The enveloppe $\mathrm{X}$ of an individual $\mathrm{Y}$ is the maximum limit1 of $\mathrm{Y}$ :

enveloppe $(X, Y) \equiv_{\operatorname{def}} \operatorname{tp}(X, Y) \wedge \forall Z[\lim 1(Z, Y) \Leftrightarrow \operatorname{tp}(Z, X)]$.

The notion of limit1 being thus defined, we can now state that a limit2 is a "boundary" between two individuals which are themselves of the limit1 type:

$\lim 2(\mathrm{X}, \mathrm{Y}) \quad \equiv_{\operatorname{def}} \exists \mathrm{Z} \quad[\lim 1(\mathrm{Y}, \mathrm{Z}) \wedge$ ᄀenveloppe(Y,Z) $\wedge \operatorname{vide}(\mathrm{i}(\mathrm{X}))$ $\wedge \operatorname{tp}(X, Y) \wedge \forall \mathrm{T}[\operatorname{tp}(\mathrm{T}, \mathrm{X}) \Rightarrow \exists \mathrm{W}[\lim 1(\mathrm{~W}, \mathrm{Z}) \wedge \operatorname{ec}(\mathrm{W}, \mathrm{T}) \wedge \operatorname{ec}(\mathrm{W}, \mathrm{Y})]]]$.

Similarly we regard a limit 3 as a "boundary" between two individuals of the limit2 category. In short, surfaces, lines and points satisfy the conditions of a limit1, lines and points those of a limit 2 whereas individuals of the limit 3 category are exclusively points.

On the basis of this information it is possible to determine the nature of the spatial referents handled in the system (the predicate con "is connected" is defined elsewhere in the theory):

$$
\begin{aligned}
& \operatorname{surface}(X, Y) \equiv_{\operatorname{def}} \operatorname{con}(X) \wedge \lim 1(X, Y) \wedge \neg \exists Z \lim 2(X, Z) \\
& \operatorname{ligne}(X, Y) \equiv_{\operatorname{def}} \operatorname{con}(X) \wedge \lim 2(X, Y) \wedge \neg \exists Z \lim 3(X, Z) \\
& \operatorname{point}(X, Y) \equiv_{\operatorname{def}} \operatorname{con}(X) \wedge \lim 3(X, Y) .
\end{aligned}
$$

These limit concepts play a great part in the formalization of ILNs like dessus 'top extremity', bord 'edge', angle 'corner', etc.

Contact seems to be another fundamental notion for the processing of space in language. In fact, the notion of contact gives rise to two different interpretations. The first one called "strong contact" covers cases in which the two entities in contact are assumed to "share some boundary points" (not the points we just introduced, which are in fact individuals). This type of contact corresponds exactly to the situations described by the predicate of external 
connection $(\mathrm{ec})$ : $\operatorname{scont}(\mathrm{X}, \mathrm{Y}) \equiv_{\mathrm{def}} \mathrm{ec}(\mathrm{X}, \mathrm{Y})$. A second category of contact (also called "weak contact") which appears very often in the language, includes all the configurations for which the entities are supposed not to have point in common although they are touching together. As it has been stated in (Vieu 1991), this weak contact is only compatible with a non-classical distance in which two points situated at a null distance from each other are not necessarily identical. An entity $\mathrm{X}$ is considered to be in contact with an entity $\mathrm{Y}$ if the closure of any open element containing $\mathrm{X}$ is connected to $\mathrm{Y}$ ( $\mathrm{a}^{*}$ denotes the universal individual):

$$
\begin{gathered}
\operatorname{cont}(\mathrm{X}, \mathrm{Y}) \equiv_{\operatorname{def}} \neg \mathrm{c}(\mathrm{X}, \mathrm{Y}) \wedge \forall \mathrm{Z}\left[\left[\neg\left(\mathrm{Z}={ }_{\mathrm{s}} \mathrm{a}^{*}\right) \wedge \mathrm{op}(\mathrm{Z}) \wedge \mathrm{p}(\mathrm{X}, \mathrm{Z})\right] \Rightarrow\right. \\
\mathrm{c}(\mathrm{c}(\mathrm{Z}), \mathrm{Y})] .
\end{gathered}
$$

Although we used this intuition to describe some predicates, the individuals handled in B.L. Clarke's calculus are not interpreted as sets of points, as we argued for in the introduction of this section. On the contrary, the author indicates in (Clarke 1985) a way to introduce points in its system as sets of individuals. This definition based on the filter technique consists in characterizing points through the individuals (connected two by two) "containing them". We proved in (Vieu 1991) that the definition in terms of filters worked correctly for interior points, but was not right for boundary ones. Actually, its application to boundary points entails that when two individuals are externally connected, any individual is also connected to them (which is a serious restriction on the nature of the modelled worlds). We therefore proposed an alternative definition for boundary points which enables us to represent the limit concept from those boundary points. Whereas, under the atomicity condition, interior points (whose definition is identical to that introduced by B.L. Clarke) each correspond to an atom (which generates the whole set of individuals including it), this is not the case for boundary points. However, the notion of base of a boundary point is defined as the minimal set of individuals generating the whole set defining the point. The definition of a boundary $\Gamma$ of an individual $X$ (a set of $X$ 's boundary points) and that of the base of $\Gamma$ restricted to $X$ associated with various constraints of minimal thickness are then used to formalize the various limits. The definition of a limit in terms of individuals introduced above and this definition based on points provide identical results. 
As already mentioned, on the geometrical level of our system we do not only take into account topological data but we also integrate some important concepts of projective geometry.

\subsection{Projective geometry}

In this module we deal with very important notions such as straight line, oriented straight line, position of a point on a straight line, etc. We have above all to make it clear that an important assumption of our study is based on the delimitation of the universe of spatial entities we describe and process (essentially with respect to their shape). So, at least for the analysis of ILNs, we restrict the research field to solid, undeformable and connected objects that also have a normal usefulness. Here we deal with a class of objects whose shape is roughly parallelepipedic, cylindrical or spherical.

We associate a system of orthogonal axes $(\mathrm{x}, \mathrm{y}, \mathrm{z})$ with the spatial referent of every entity having the object status according to its dimensionality and shape. For example, three orthogonal axes are associated with a parallelepiped or a sphere but, whereas in the case of the parallelepiped these axes are each parallel to a pair of sides, in the case of the sphere their position is not exactly determined with respect to the whole object ${ }^{5}$. As every axis is attached to an entity, it will be identified by means of a pair (X,Axe) specifying the entity and the axis's name. In this notation, brackets play the part of a function associating the spatial referent of the axis with an entity and an axis's name. We must underline that, from the same axis, it is possible to define two oriented straight lines or directions. Because they depend on the axis, oriented straight lines are noted with the triplet (X,Axe,Dir) in which the variable Dir denotes a direction name. Directions handled on the geometrical level are called abstract because they do not call for any concrete orientation like top, bottom, left, etc. In fact, the assignment of a concrete orientation to an abstract direction is a completely functional process that we model at the functional level of the system. The sorted variable Dir introduced in the notation above in order to designate an abstract direction takes its values in the set $\{\mathrm{p}, \mathrm{op}\}$, whereas the constants + and - point out the concrete orientations appearing at the functional level. In the same way, the variable Axe representing an abstract direction is instantiated by the values $\{\mathrm{x}, \mathrm{y}, \mathrm{z}\}$ as opposed to 1, 2 and 3 which denote the vertical, frontal and lateral concrete 
axes, respectively. So, these two sorted variables do not take their values in the entity set.

In our representation we project the spatial referent of an entity $\mathrm{Y}$ (noted $\operatorname{sref}(\mathrm{Y})$ ) on the axes generated by an entity $\mathrm{X}$ of which $\mathrm{Y}$ is a part, and we specify with an interval Int, the axis portion filled by that projection. All this information is integrated in the predicate $\operatorname{proj}(\operatorname{sref}(\mathrm{Y}),(\mathrm{X}, \mathrm{Axe}), \mathrm{Int})$. The variable Int represents the interval [Exta,Extb] of (X,Axe) resulting from the projection of $\operatorname{sref}(\mathrm{Y})$ on the axis (X,Axe). The spatial referent of an entity is projected on the axes of the entities which immediately contain it $^{6}$ and not on every axis system of the entities of which it is a part.

We already said that, for the same abstract axis (X,Axe), it was possible to define two abstract directions (X,Axe,Dir) that we distinguish with the values $\mathrm{p}$ or op of the variable Dir. From an abstract direction (X,Axe,Dir) of an axis (X,Axe), we can build the relation "inf" on the set of projection points expressing that a point precedes another in a direction. A and $B$ being two projection points on an axis, they verify one of the three following configurations (where eg $(\mathrm{A}, \mathrm{B})$ means that $\mathrm{A}$ equals $\mathrm{B}$ ):

- $(\inf (\mathrm{A}, \mathrm{B}), \mathrm{Dir})$

- $(\inf (\mathrm{B}, \mathrm{A}), \mathrm{Dir})$

- $\operatorname{eg}(\mathrm{A}, \mathrm{B})$.

We use these relations to situate the projection points present on an axis with respect to each other. We specify the relative locations of the projection points on an axis by means of the predicate $\operatorname{rel}((\mathrm{X}, \mathrm{Axe}), \mathrm{List})$ in which the variable List denotes a list of relations like the one we defined. Thanks to these order relations, some operators between intervals that are very similar to those introduced by J. Allen (Allen 1984) for time can be defined (Aurnague 1991). For example we succeed in calculating that an interval [Exta1,Extb1] is more advanced in one direction (noted as plus_dir([Exta1,Extb1],[Exta2,Extb2],(X,Axe,Dir))) or included (inclus([Exta1,Extb1],[Exta2,Extb2],(X,Axe,Dir))) in another interval [Exta2,Extb2].

This system of axes and projections is fundamental in stating the semantic definition of ILNs as haut 'top', bas 'bottom', dessus 'top extremity', dessous 'bottom extremity', etc. (we will give them on the functional level). 
Another aspect of projective geometry consists in specifying the notions of straight lines, oriented straight lines, etc., through definitions based on the primitive relation "A is situated between $\mathrm{B}$ and $\mathrm{C}$ " between points. An important aim now is to specify the system of axes associated with the spatial referent of an entity in terms of this straight line definition. As the determination of these axes relies mostly on the shape of the objects, we would want to deal with the information linked to shape in a qualitative way (as we do for the other types of data), which seems to be very difficult.

The last point we deal with in geometry is the notion of distance that we introduce by means of the primitive relation "B is closer to A than $\mathrm{C}$ is". As we pointed out it before, the formalization of the intuitive contact implies that this distance should be a non-classical one for which two points situated at a null distance from each other can be considered as distinct (in case of weak contact). We can conclude the presentation of this level by saying that we obtained a complete relational geometry. In fact, the information processed at this level is not restricted to the spatial domain since the individuals handled here are really spatiotemporal referents of the entities. Consequently, we introduce purely temporal relations which are similar to those we defined up to now for the space-time structure and we also express the links between these two data types.

Figure 2 provides a partial description of a cupboard which uses most of the geometrical tools we have shown up to now. The first table of Figure 2 provides the various elements appearing in the description and the symbols by which we refer to them. Some elements (noted in standard characters) are really entities (and more precisely objects), which means that a speaker can individualize them. Other elements are simply spatial referents whose presence is needed for the topological consistency of the spatial structure. The second table shows the connections between the different spatial referents (note that all the information is encoded with the primitive of connection). These connections allow us to calculate, by means of the definitions and axioms of the theory, the inclusions and the external connections between spatial referents. Later, on the functional level, the system deduces component/assembly relations ${ }^{7}$ for the entities having the object status. Lastly, the system determines (by using the limit definitions) the nature of some spatial referents (surfaces, lines or points). 
As we showed in the second section, geometrical properties are insufficient to grasp the semantics of spatial expressions and, consequently, we need to take into account on a second level the functional characteristics of the entities.

\section{The functional level}

At this level we deal with the orientation process, plural structures as well as some concepts of naive physics such as stabilization or containment. As all these properties directly concern the entities themselves, we handle variables which represent entities and not simple portions of space (as is the case on the geometrical level). These are designated through the "function" sref. It is also at this level that we introduce the "crude" semantic definitions of the spatial expressions we study.

\subsection{Orientations}

We already mentioned that only abstract directions are handled in the geometrical module. The orientation process consists in mapping an abstract orientation on a concrete one. Since the assignment of a concrete orientation depends on properties of the object itself or of its context, it must be formalized on the functional level. This phenomenon appears very clearly in intrinsic orientation configurations for which the functions of the different parts of an entity give it a canonical position in space (with respect to the vertical axis, the user, etc.), entailing the intrinsic orientation. For instance, the intrinsic front of a computer is derived directly from the usual position of its screen. Therefore, we represent the orientation by means of the predicate orient $((\mathrm{X}, \mathrm{Axe}, \mathrm{Dir}),(\mathrm{A}, \mathrm{D}), \mathrm{V})$ which specifies the coincidence between the abstract direction (X,Axe,Dir) of X (e.g.: the direction (ar,X,p) of the cupboard in Figure 2) and the concrete orientation (A,D) (e.g.: $(1,+)$ which denotes the top or the upper orientation $)^{8}$. The third term of the predicate points out the entity responsible for this mapping process, which can be the entity $\mathrm{X}$ itself (in this case variables $\mathrm{V}$ and $\mathrm{X}$ are identical and the orientation is intrinsic) or another entity in the context ( $\mathrm{V}$ and $\mathrm{X}$ denote distinct entities and the orientation is deictic) ${ }^{9}$. This predicate is used to elaborate various rules for the calculation and processing of orientations. For example, we can deduce an intrinsic orientation of an entity $\mathrm{X}$ from the fixedness of one of its 
parts $\mathrm{Y}$ or state that every vertical deictic orientation is induced by gravity. This last property is expressed with the following rule (in which the contextual entity g symbolizes gravity):

$\forall \mathrm{X} \forall$ Axe $\forall$ Dir $\forall \mathrm{V}[[\operatorname{orient}((\mathrm{X}$, Axe,Dir $),(1, \mathrm{D}), \mathrm{V}) \wedge \neg(\mathrm{X}=\mathrm{V})] \Rightarrow$ $\operatorname{orient}((X, A x e, D i r),(1, D), g)]$.

Because we restricted the type of entity processed by the system, we introduce, again for the analysis of ILNs, some conditions on orientations. First, the texts studied are "instantaneous" in the sense that the entities described as well as the speaker do not change in position with respect to one another. Moreover, we make the hypothesis that an entity is oriented at one moment by a unique speaker. The result of the instantaneous constraint (which induces the immobility of both the entity and the orientor) can be stated by means of the two following postulates:

- $\forall \mathrm{X} \forall$ Axe1 $\forall$ Dir1 $\forall$ Axe $2 \forall$ Dir2 $\forall \mathrm{V} \forall$ A $\forall$ D

$\neg[\operatorname{orient}(\mathrm{X}, \mathrm{Axe} 1, \mathrm{Dir} 1),(\mathrm{A}, \mathrm{D}), \mathrm{V}) \wedge \operatorname{orient}((\mathrm{X}, \mathrm{Axe} 2, \mathrm{Dir} 2),(\mathrm{A}, \mathrm{D}), \mathrm{V}) \wedge$

$[\neg($ Axe1 $=$ Axe $) \vee \neg($ Dir1=Dir2) $]]$

- $\forall \mathrm{X} \forall$ Axe $\forall$ Dir $\forall \mathrm{V} \forall$ A $1 \forall$ D $1 \forall$ A2 $\forall$ D2

$\neg[\operatorname{orient}(\mathrm{X}, \mathrm{Axe}, \mathrm{Dir}),(\mathrm{A} 1, \mathrm{D} 1), \mathrm{V}) \wedge \operatorname{orient}((\mathrm{X}, \mathrm{Axe}, \mathrm{Dir}),(\mathrm{A} 2, \mathrm{D} 2), \mathrm{V}) \wedge$

$[\neg(\mathrm{A} 1=\mathrm{A} 2) \vee \neg(\mathrm{D} 1=\mathrm{D} 2)]]$.

The first constraint states that the same concrete orientation cannot be assigned to two different abstract directions whereas the second one prevents the same abstract direction from coinciding with two distinct concrete orientations. In both cases, those multiple orientations can be the result of a movement of the entity or of the orientor-speaker.

Another aspect related to orientation which we deal with on this functional level consists in determining the central interval of an axis. As it is shown in (Vandeloise 1986), such a determination does not only depend on geometrical properties of symmetry because it is greatly conditioned by functional features. After identifying this central interval, we can define two poles surrounding it, each in one of the two directions associated with the axis.

All these orientational tools are used in the semantic definitions of ILNs as haut 'top', bas 'bottom', devant 'front extremity', etc., expounded in (Aurnague 1991) and allow us to model the component of the semantics of sur 'on' relative to the position of the entities on the vertical axis. For 
instance, we represent the semantic content of the ILN haut 'top' with the following formula:

$\forall \mathrm{X} \forall$ Axe $\forall$ Dir $\forall \mathrm{V} \forall \mathrm{N}$

[orient((X,Axe,Dir),(1,+),V) $\wedge$ natur_or((X,Axe,Dir $),(1,+), \mathrm{V}, \mathrm{N})] \Rightarrow$ $\operatorname{haut}(\mathrm{Y}, \mathrm{X}, \mathrm{N}) \equiv_{\text {def }} \mathrm{ds} \_$pôle(Y,(X,Axe,Dir) $) \wedge$

$\forall \mathrm{Z}$ [ds_pôle(Z,(X,Axe,Dir) $) \Rightarrow \operatorname{part}(\mathrm{Z}, \mathrm{Y})]$.

This definition states that when the abstract direction (X,Axe,Dir) of an entity $X$ receives a deictic or intrinsic (variable $N$ ) upper orientation, the maximum entity $\mathrm{Y}$ situated in the pole whose abstract direction is (X,Axe,Dir) constitutes the top of $\mathrm{X}$. In this definition, it is clear that functional aspects such as orientation directly arise in the semantics of spatial expressions. This observation confirms the assertion of E. Lang who, in his work about dimensional adjectives (Lang 1990) in which the same functional aspects of orientation appear, writes that "the semantic analysis of these linguistic items has to be justified in terms of non-linguistic conceptual structure formation".

\subsection{The structure of the entities}

On the geometrical level, there is only one relation to link a part to a whole, namely the spatial inclusion (noted p). As a result, it is impossible to describe a spatial referent as having a specific internal structure.

However, we often give a particular structure to the entities, sometimes just by choosing the noun phrase used to refer to an object. For instance, the rice is conceived as a continuous entity whereas the rice grains is definitely a discrete one (i.e. a collection). At the same time, there exist several partwhole relations (also called meronomies) between the entities: "membercollection" (e.g. Texas is a member of the USA), "component-assembly" (e.g. this wheel is a part of this car), etc. This diversity alone precludes their direct identification with spatial inclusion. Besides, meronomies cannot be represented on the geometrical level, because they rely on functional aspects of the entities. In particular, the relation "member-collection" cannot be reduced to a mere inclusion as, among other things, it is not transitive (The USA are a member of UNO whereas Texas is not).

We felt that dealing with the internal structures of the entities was part of our work for several reasons. Firstly, ILNs designate parts of a whole, i.e. they describe a kind of meronomy; in addition, we will see in the next

M. Aurnague - L. Vieu 
section that the preposition dans 'in' can be used to describe meronomies. Secondly, structural relations help explain what the links are between the different entities used to refer to the same physical object. We wanted to be able to differentiate these entities; at the same time, it is desirable to express how they are related. At last, we can mention that on the geometrical level, any sum of individuals is a new individual whereas few of these sums correspond to actual entities. This can be explained by the fact that we conceptualize as entity only what has some kind of internal structure; the knowledge of these structures then takes on another sort of importance.

\subsubsection{The plural structure}

The notion of collection is important in NL: $\operatorname{most}^{10}$ plural noun phrases (e.g. Jean et Marie 'John and Mary', les arbres 'the trees'...) refer to a collection, and many singular noun phrases too (e.g. le couple Dupont 'the couple Dupont', la forêt 'the forest'...). Two types of relations are associated with this notion: the relation "member-collection" (e.g. between one tree and the forest) and the relation "subcollection-collection" (e.g. between a smaller group of trees and the forest). To represent them, we have taken up the lattice structure introduced by G. Link in his "Logic of Plurals and Mass Terms" (Link 1983: 311-316).

In this structure, also called the "plural" lattice, the entities denoted by singular noun phrases in the discourse analysed are represented as atoms, whereas the entities denoted by plural noun phrases are non-atomic elements. The latter are put in relation to their members and to their sub-collections by the ordering relation (noted $\leq_{\mathrm{i}}$ ) of the lattice ${ }^{11}$. It must be noted that a collection referred to by a singular noun phrase appears as an atom in this structure, therefore their members are not directly related to them. Still, this atomic entity and the corresponding plural entity (e.g. the forest and the trees) are linked through the existence of another entity: the portion of matter making both of them up. Portions of matter are atoms in the plural lattice, but form themselves a new semilattice ${ }^{12}$ structure -a "matter" semilatticewhere the new ordering relation (noted $\leq$ ) is interpreted as "is a portion of". Obviously, the two ordering relations are not unrelated: if we have $\mathrm{x} \leq_{\mathrm{i}} \mathrm{y}$ then we have $h(x) \leq h(y)$, where $h$ is the homomorphism between semilattices that gives each entity its corresponding portion of matter. This function $h$, restricted to the set of entities which are portions of matter (a subset of the set 
of the plural lattice's atoms), is the function identity. The portions of matter are real entities people can refer to by what is called mass terms (e.g. the water in my glass, the gold of my ring), and the matter semilattice, together with some other tools, enables G. Link to deal with properties specific to mass terms such as cumulative reference ${ }^{13}$.

The fact that singular noun phrases referring to collections are not directly represented as non-atomic elements is a very useful characteristic of G. Link's formalism. Indeed, the two entities the trees and the forest are distinct: the forest, not the trees, implies that the collection of trees is closely built-up in space. In the same way, there are several possibilities of grouping elements in a collection. G. Link gives the example of several decks of cards: the decks and the cards are two plural entities describing the same portion of matter, and they are different since, in particular, counting them gives different results. Furthermore, the distinction between plural and atomic collections makes it possible to account for the non-transitivity of the relation "member-collection": Texas can be a member of the plural entity grouping all of the American states (Texas and Alabama and ...), itself linked to the atom the USA by the fact that they have the same "portion of matter", while the $U S A$ is a member of the plural entity grouping all of the UNO nations and without Texas being a member of $U N O$. In addition, when a collection is described by a singular noun phrase which is a mass term (e.g. the rice in this bowl), its identification with the corresponding plural entity (e.g. the rice grains in this bowl) would be disastrous because, as it is claimed by many philosophers and linguists (Quine 1960) (Bunt 1985)..., mass terms do behave as if they were describing fully continuous entities.

However, E. Bach has emphasized the difficulty in (Bach 1986) for any entity to pick the right entity corresponding to the portion of matter which makes it up. He gives as an example the entity the snowman which should be linked by the function $\mathrm{h}$ to the snow making up the snowman, but this portion of matter can also be described as being constituted by the water making up the snow which makes up the snowman and actually, there is no reason to stop here since the water itself is made up of hydrogen and oxygen, etc... It must be noted that these portions of matter are different entities since snow and water have different properties. So, even though we accept the presence of portions of matter as atoms of the plural lattice and the fact that any entity (including other portions of matter) may be linked to a portion of

M. Aurnague - L. Vieu 
matter through a "constitution" relation, we think that the role of the matter semilattice has to be played by the spatial structure introduced on the geometrical level.

In our proposition, to be consistent with the pseudo-Boolean structure of the geometrical level, we have removed the null element from G. Link's plural lattice and so on the functional level too, we only have a pseudo-lattice. For this reason, we have chosen to represent this plural structure in a mereologic way instead of representing it classically according to set theory. The chosen primitive is $\leq$ (noted $\leq_{\mathrm{i}}$ in G. Link's logic), the part-of relation of mereology.

The following are the three postulates required:

- $\forall \mathrm{X} \forall \mathrm{Y} \forall \mathrm{Z}((\mathrm{X} \leq \mathrm{Y} \wedge \mathrm{Y} \leq \mathrm{Z})=>\mathrm{X} \leq \mathrm{Z}))$

- $\forall \mathrm{X} \forall \mathrm{Y}((\mathrm{X} \leq \mathrm{Y} \wedge \mathrm{Y} \leq \mathrm{X})<=>\mathrm{X}=\mathrm{Y})$

- $\forall \alpha(\exists \mathrm{X} X \varepsilon \alpha=>\exists \mathrm{Y}$ fu' $(\mathrm{Y}, \alpha)) \quad$ (here too, the Greek alphabet is used to denote sets of entities);

along with the following definitions:

- $\mathrm{o}^{\prime}(\mathrm{X}, \mathrm{Y}) \equiv_{\mathrm{def}} \quad \exists \mathrm{Z}(\mathrm{Z} \leq \mathrm{X} \wedge \mathrm{Z} \leq \mathrm{Y}) \quad \mathrm{X}$ overlaps $\mathrm{Y}$

- $\operatorname{dr}^{\prime}(X, Y) \equiv_{\operatorname{def}} \neg \mathrm{o}^{\prime}(X, Y) \quad X$ is discrete from $Y$

- at' $^{\prime}(\mathrm{X}) \equiv_{\text {def }} \quad \forall \mathrm{Y}(\mathrm{Y} \leq \mathrm{X}=>\mathrm{Y}=\mathrm{X}) \quad \mathrm{X}$ is atomic

- $\mathrm{f}^{\prime}(\mathrm{X}, \alpha) \equiv_{\mathrm{def}} \quad \forall \mathrm{Y}(\mathrm{Y} \varepsilon \alpha=>\mathrm{Y} \leq \mathrm{X}) \wedge$

$\neg \exists \mathrm{Y}\left(\mathrm{Y} \leq \mathrm{X} \wedge \forall \mathrm{Z}\left(\mathrm{Z} \varepsilon \alpha=>\operatorname{dr}^{\prime}(\mathrm{Z}, \mathrm{Y})\right)\right) \quad \mathrm{X}$ is the fusion of the set $\alpha$

- $\mathrm{Z}=\mathrm{X} \oplus \mathrm{Y} \equiv_{\operatorname{def}} \quad \mathrm{f}^{\prime}(\mathrm{Z},\{\mathrm{X}, \mathrm{Y}\}) \quad \mathrm{Z}$ is the sum of $\mathrm{X}$ and Y

- $\mathrm{Z}=\mathrm{X} \otimes \mathrm{Y} \equiv_{\operatorname{def}} \quad \mathrm{f}^{\prime}(\mathrm{Z},\{\mathrm{U}: \mathrm{U} \leq \mathrm{X} \wedge \mathrm{U} \leq \mathrm{Y}\}) \quad \mathrm{Z}$ is the intersection of $\mathrm{X}$ and $\mathrm{Y} ; \mathrm{Z}$ exists only if $\mathrm{o}^{\prime}(\mathrm{X}, \mathrm{Y})$

$\bullet \mathrm{Z}=\sim \mathrm{X} \equiv_{\mathrm{def}} \quad \mathrm{f}^{\prime}\left(\mathrm{Z},\left\{\mathrm{Y}: \mathrm{dr}^{\prime}(\mathrm{X}, \mathrm{Y})\right\}\right) \quad \mathrm{Z}$ is the complement of $\mathrm{X}$; $\mathrm{Z}$ exists only if $\mathrm{X}$ is not the collection of all atoms.

It is necessary to link the plural structure of the entities and the spatial structure:

$\forall \mathrm{X} \forall \mathrm{Y}(\mathrm{X} \leq \mathrm{Y}=>\mathrm{p}(\operatorname{sref}(\mathrm{X}), \operatorname{sref}(\mathrm{Y})))$

We mentioned above that an atomic collection and the corresponding plural collection were linked through the identity of their portions of matter: in our case, the link would be made through the identity of their spatial referents. However, this may raise ambiguities because different plural entities can describe the same concrete object (i.e. can have the same spatial

M. Aurnague - L. Vieu 
referent), as seen with the example of the decks of cards. Moreover, we have seen that in the case of mass terms describing collections ${ }^{14}$, it is not desirable to link them to a plural entity. Therefore, we introduce the relation "is the collection" that links a singular (i.e. atomic) entity designating a collection to the right plural entity. This relation is noted est-coll. It satisfies the following postulates:

- $\forall \mathrm{X} \forall \mathrm{Y}\left(\right.$ est-coll $\left.(\mathrm{X}, \mathrm{Y})=>\left(\operatorname{at}^{\prime}(\mathrm{X}) \wedge \neg \operatorname{at}(\mathrm{Y})\right)\right)$

- $\forall \mathrm{X} \forall \mathrm{Y}\left(\right.$ est-coll $\left.(\mathrm{X}, \mathrm{Y})=>\operatorname{sref}(\mathrm{X})=_{\mathrm{s}} \operatorname{sref}(\mathrm{Y})\right)$

- $\forall \mathrm{X} \forall \mathrm{Y} \forall \mathrm{Z}((\mathrm{est}-\operatorname{coll}(\mathrm{X}, \mathrm{Y}) \wedge$ est-coll $(\mathrm{X}, \mathrm{Z}))=>\mathrm{Y}=\mathrm{Z})$

\subsubsection{Meronomies}

With the help of the preceding plural structure, we are now able to define the various meronomies that can be expressed in NL.

We already mentioned the two meronomies: "member-collection" and "subcollection-collection". We consider two more, namely "componentassembly" (e.g. my nose is part of my head) and "piece-whole" (e.g. this shard was part of my cup). Actually, we have shown in (Vieu 1991: 163172) that another pair of meronomies should be added in order to cover the whole range of part-whole relations: "portion-whole" (e.g. this is a portion of the strawberry pie mum made) and "substance-whole" (e.g. there is butter in this cake), but as the study of mass term properties goes beyond the scope of this paper, we decided to set them aside.

The relation "component-assembly" has to be distinguished from the relation "piece-whole" on the grounds that in the first, the part has a welldefined function with respect to its whole, whereas in the latter, the part is arbitrarily defined in its whole (e.g. South-West of France, the top of the ball). In the first case, the function of the part usually gives it well-defined boundaries, but in the second case the part must often be designated by describing its boundaries, for instance, using an ILN. Moreover, a component can be unconnected (for instance, a set of spanners in a tool box), whereas a piece is only a connected part.

"member-collection":

$$
\text { el-coll }(X, Y) \equiv_{\text {def }} \operatorname{at}^{\prime}(X) \wedge((\neg \operatorname{at}(Y) \wedge X \leq Y) \vee
$$

$\exists \mathrm{Z}(\mathrm{est}-\operatorname{coll}(\mathrm{Y}, \mathrm{Z}) \wedge \mathrm{X} \leq \mathrm{Z}))$ 
"subcollection-collection":

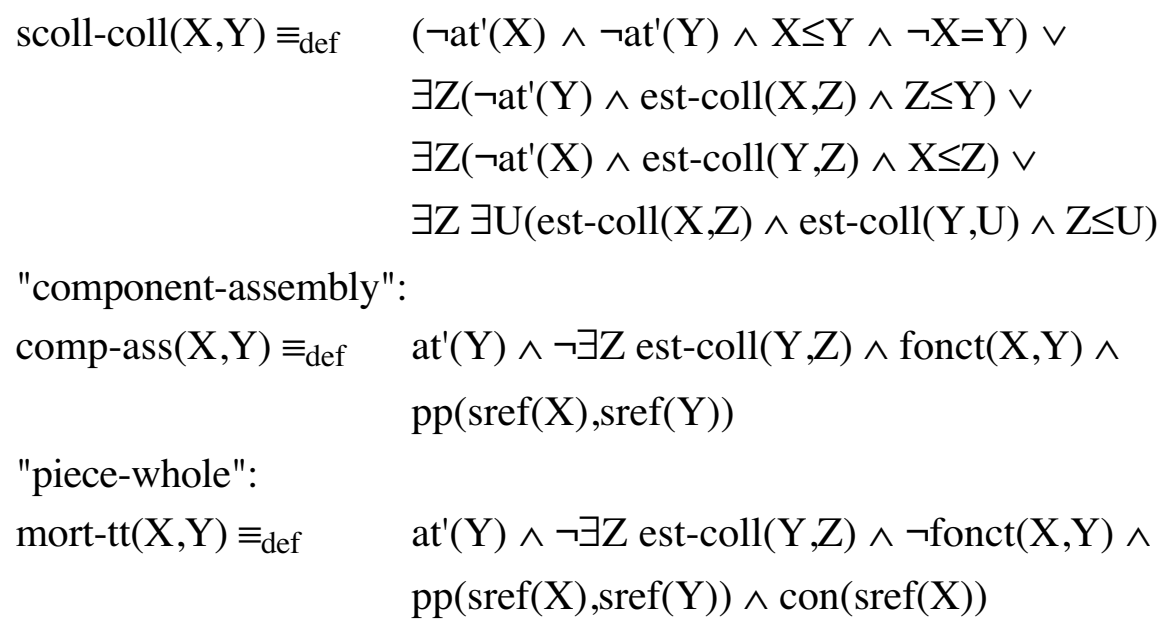

Finally, we group all four cases in one predicate in order to represent the part-whole relations in an unspecified way:

$$
\begin{aligned}
\operatorname{part}(\mathrm{X}, \mathrm{Y}) \equiv_{\text {def }} & \text { el-coll }(\mathrm{X}, \mathrm{Y}) \vee \operatorname{scoll}-\operatorname{coll}(\mathrm{X}, \mathrm{Y}) \vee \operatorname{comp}-\operatorname{ass}(\mathrm{X}, \mathrm{Y}) \vee \\
& \text { mort-tt }(\mathrm{X}, \mathrm{Y})
\end{aligned}
$$

We also need two postulates for the relation fonct $(X, Y)$ to express that $\mathrm{X}$ has some kind of function with respect to $\mathrm{Y}$. This relation is not deeply analysed in this work, but it is enough for our immediate purposes to state the transitivity of "fonct" and the fact that if a part has no function with respect to a whole, it also has no function with respect to an all-inclusive entity:

$$
\begin{gathered}
\forall \mathrm{X} \forall \mathrm{Y} \forall \mathrm{Z}((\operatorname{fonct}(\mathrm{X}, \mathrm{Y}) \wedge \operatorname{fonct}(\mathrm{Y}, \mathrm{Z}))=>\operatorname{fonct}(\mathrm{X}, \mathrm{Z})) \\
\forall \mathrm{X} \forall \mathrm{Y} \forall \mathrm{Z}((\operatorname{part}(\mathrm{X}, \mathrm{Y}) \wedge \neg \operatorname{fonct}(\mathrm{X}, \mathrm{Y}) \wedge \operatorname{part}(\mathrm{Y}, \mathrm{Z}))=> \\
\neg \operatorname{fonct}(\mathrm{X}, \mathrm{Z}))
\end{gathered}
$$

It is worth noting that we do not have as a theorem $\forall \mathrm{X} \quad \forall \mathrm{Y}$ $(\operatorname{pp}(\operatorname{sref}(\mathrm{X}), \operatorname{sref}(\mathrm{Y}))=>\operatorname{part}(\mathrm{X}, \mathrm{Y}))$, in particular, since if $\mathrm{Y}$ is a collection, only its members and its subcollections can be considered as parts.

\subsubsection{Classification of entities}

We will see, in particular for the preposition dans 'in', that the semantic study of spatial markers shows the necessity of distinguishing several classes of entities. These are: the objects (e.g. a tree, a forest, Mary, a piece of gold), the locations (e.g. a country, a crossroads, the Atlantic Ocean, the Pyrénées, my garden, a forest) and the space portions (e.g. the interior of a box, a hole in the sheet, a cave in the mountain, the middle of (the interior of) the room $)^{15}$.

M. Aurnague - L. Vieu 
There are two important facts to note. First, the space portions are always described with the help of another entity which is an object or a location. It has been underlined in section 3 that the spatial referents of the entities are determined by their physical matter. This is not directly the case for space portions, for they are immaterial; still, they are functionally determined from some material entity(ies), so their spatial referents are geometrically determined from its (their) spatial referent $(\mathrm{s})^{16}$.

Second, the same noun phrase can designate different entities. For instance, 'the forest' can be an object: the collection of trees (or even the collection of all kinds of beings living in that collection of trees) and it can be a location: the portion of ground on which the trees grow. The same holds for many noun phrases: a city is either a collection of houses, or a location; a sea or a river is either a water body, or a location; a mountain is either a heap of earth, or a location.

But not every entity can belong to a definite class. There is no rule to prevent someone from forming either the plural noun phrase John and the $U S A$ in NL or the corresponding plural entity in the plural structure. However, we make the assumption that every atomic entity always belongs to one of the three classes. This assumption is rather strong because it implies that there is no singular noun phrase describing a "mixed" collection such as John and the USA. This may be a drawback of our formalism, but we did not find any counter-example to this assumption. As a consequence, we add the postulates:

- $\forall X\left(\operatorname{at}^{\prime}(X)=>(\operatorname{obj}(X) \vee \operatorname{loc}(X) \vee \operatorname{sp}-\operatorname{port}(X))\right)$

- $\forall \mathrm{X}(\operatorname{obj}(\mathrm{X})=>(\neg \operatorname{loc}(\mathrm{X}) \wedge \neg$ sp-port $(\mathrm{X})))$

- $\forall \mathrm{X}(\operatorname{loc}(\mathrm{X})=>(\neg \mathrm{obj}(\mathrm{X}) \wedge \neg \mathrm{sp}-\operatorname{port}(\mathrm{X})))$

- $\forall \mathrm{X}(\operatorname{sp}-\operatorname{port}(\mathrm{X}) \Rightarrow(\neg \mathrm{obj}(\mathrm{X}) \wedge \neg \operatorname{loc}(\mathrm{X})))$

Finally, we can state that in a part-whole relation the part and the whole are of the same type, restricting this postulate to the cases where the whole is not a plural entity (which could be a mixed entity):

$\forall \mathrm{X} \forall \mathrm{Y}\left(\left(\operatorname{part}(\mathrm{X}, \mathrm{Y}) \wedge \operatorname{at}^{\prime}(\mathrm{Y})\right)=>((\operatorname{obj}(\mathrm{X}) \wedge \operatorname{obj}(\mathrm{Y})) \vee\right.$

$$
(\operatorname{loc}(\mathrm{X}) \wedge \operatorname{loc}(\mathrm{Y})) \vee(\mathrm{sp}-\operatorname{port}(\mathrm{X}) \wedge \operatorname{sp} \text {-port }(\mathrm{Y}))))
$$

The role of this postulate is in particular to exclude the interpretation of a mere spatial inclusion between an object and a space portion as a part-whole relation. In fact, in la boite est dans l'intérieur de l'armoire 'the box is in the 
cupboard's interior', the box is certainly not conceived as a part of the interior.

In addition, it is necessary to modify the definition of the "piece-whole" meronomy, which was only conceived for material entities (objects and locations). For space portions, we actually need to take into account the material entity that determines it. The interior of a drawer of a cupboard is a part (piece-whole) of the interior of the cupboard: the two space portions are determined by two objects linked by a meronomy (here, componentassembly). This is not the case for the interior of a box situated in the cupboard: the two space portions have no conceptual link, neither do the two objects. To allow for this modification, we add the following postulates, where the relation $\operatorname{det}(\mathrm{X}, \mathrm{Y})$ should be read as "X determines $\mathrm{Y}$ ":

- $\forall \mathrm{X}(\operatorname{sp}-\operatorname{port}(\mathrm{X})=>\exists \mathrm{Y}((\operatorname{obj}(\mathrm{Y}) \vee \operatorname{loc}(\mathrm{Y})) \wedge \operatorname{det}(\mathrm{Y}, \mathrm{X})))$

- $\forall \mathrm{X} \forall \mathrm{Y} \forall \mathrm{T} \forall \mathrm{U}((\operatorname{mort}-\mathrm{tt}(\mathrm{X}, \mathrm{Y}) \wedge \mathrm{sp}-\operatorname{port}(\mathrm{X}) \wedge \operatorname{det}(\mathrm{T}, \mathrm{X}) \wedge$

$$
\operatorname{det}(\mathrm{U}, \mathrm{Y}))=>(\mathrm{T}=\mathrm{U} \vee \operatorname{part}(\mathrm{T}, \mathrm{U}))
$$

\subsection{The semantic definition of the prepositions: some naive physics concepts}

\subsubsection{The preposition sur}

As mentioned in section 4.1, the position of the entities on the vertical axis is a very important distinction criterion between the different cases of sur 'on' according to the kind of configuration they refer to. If the trajector is placed higher than the landmark (as in sentence (8a)), this situation is referred to as surl 'on1'. The case in which the trajector is on the same level as the landmark (as in (8b)) is called sur2 'on2'. Sur3 'on3' applies when the trajector is placed lower than the landmark (as in (8c)).

(8) a. sur1 'on1' Le livre est sur la table

'The book is on the table'

b. sur2 'on2' L'affiche est sur le mur

'The poster is on the wall'

c. $\quad$ sur3 'on3' La mouche est sur le plafond

'The fly is on the ceiling'

M. Aurnague - L. Vieu 
On the geometrical level, these various configurations give rise to three types of contact between individuals (cont1, cont 2 and cont 3 respectively). For instance, cont 1 corresponds to the situation where a piece $\mathrm{Z} 1$ of $\mathrm{X}$ is in contact with a piece $\mathrm{Z} 2$ of $\mathrm{Y}, \mathrm{Z} 1$ being higher than $\mathrm{Z} 2$. This set of conditions is expressed by the following rule in which the predicate zonecont $(\mathrm{Z} 1, \mathrm{X}, \mathrm{Y})$ denotes the contact area $\mathrm{Z} 1$ between two elements $\mathrm{X}$ and $\mathrm{Y}^{17}$ :

$$
\begin{aligned}
& \operatorname{cont} 1(X, Y) \equiv_{\text {def }} \operatorname{cont}(X, Y) \wedge \exists Z 1 \exists Z 2[\text { zonecont }(Z 1, X, Y) \wedge \\
& \text { Zonecont }(Z 2, Y, X) \wedge \text { plus_haut }(Z 1, Z 2)] \text {. }
\end{aligned}
$$

Thus comparing the relative positions of the two contact areas between the spatial referents of the entities (and not directly the relative position of those spatial referents), all sur 'on' configurations will correspond to one of the three cases mentioned above.

Apart from the geometrical characteristics of the relative position of the contact area, two important functional aspects arise in the semantics of sur 'on', namely the notions of "comparable categories" and "stabilization". Two entities $\mathrm{X}$ and $\mathrm{Y}$ belong to comparable categories if they have similar dimensions; this is noted as catcomp $(\mathrm{X}, \mathrm{Y})$. This property is calculated by comparing the projections of the spatial referents of $\mathrm{X}$ and $\mathrm{Y}$ on each axis of the triaxial system associated with an including entity $\mathrm{Z}$ (we create here a partial order relation on the projections). The projection on a particular axis can be more relevant than on the others, depending on the configuration of the entities involved. For example, in the case of a surl 'on1' (sentence (9a)) the respective sizes of the trajector and the landmark according to the vertical axis are relatively little constrained, whereas for usages of the type sur3 'on 3' it is more difficult to admit an extension of the trajector along this dimension (sentence (9b)). Thus, we use three different "catcomp" predicates (catcomp1, catcomp2, catcomp3) corresponding to the three configurations of sur 'on'. Furthermore, functional properties and nature of the entities must be taken into account in the definition of "comparable categories".

(9) a. Le vase est sur la nappe

'The vase in on the table-cloth'

b. *Le lustre est sur le plafond

*'The hanging light is on the ceiling'

M. Aurnague - L. Vieu 
Stabilization (sometimes referred to as support) is another functional concept which actually plays a major part in the semantics of the preposition sur 'on'. In our system, the predicate stabilise $(X, Y)$ indicates that an entity $\mathrm{X}$ stabilizes an entity $\mathrm{Y}$ and the following postulate shows that, contrary to the contact relation, stabilization is transitive:

$\forall \mathrm{X} \forall \mathrm{Y} \forall \mathrm{Z}$ [stabilise $(\mathrm{X}, \mathrm{Y}) \wedge$ stabilise $(\mathrm{Y}, \mathrm{Z})] \Rightarrow \operatorname{stabilise}(\mathrm{X}, \mathrm{Z})$.

Any entity stable in essence (e.g.: ground) is called intrinsic stabilizer and every entity which does not belong to that category has to be stabilized by another element in contact with it:

$\forall \mathrm{X} \neg$ stabilisateur_intrinseque $(\mathrm{X}) \Rightarrow \exists \mathrm{Y}[\neg(\mathrm{Y}=\mathrm{X}) \wedge \operatorname{stabilise}(\mathrm{Y}, \mathrm{X}) \wedge$ $\operatorname{cont}(\operatorname{sref}(\mathrm{Y}), \operatorname{sref}(\mathrm{X}))]$.

Specific postulates are also introduced in order to account for the interaction between the part-whole relation and the stabilization process. For example, if a piece $\mathrm{Z}$ of an entity $\mathrm{Y}$ stabilizes an entity $\mathrm{X}$, then $\mathrm{Y}$ stabilizes $\mathrm{X}$ :

$\forall \mathrm{X} \forall \mathrm{Y} \forall \mathrm{Z}[\operatorname{part}(\mathrm{Z}, \mathrm{Y}) \wedge \neg \operatorname{part}(\mathrm{X}, \mathrm{Y}) \wedge \operatorname{stabilise}(\mathrm{Z}, \mathrm{X})] \Rightarrow$ stabilise $(\mathrm{Y}, \mathrm{X})$.

The concept of total stabilization is defined by saying that an entity $\mathrm{Y}$ totally stabilizes another entity $\mathrm{X}$ if, obviously, $\mathrm{Y}$ stabilizes $\mathrm{X}$ and if, furthermore, every entity $\mathrm{Z}$ disjoint from $\mathrm{Y}$ and directly stabilizing $\mathrm{X}$ is itself totally stabilized by $\mathrm{Y}$. These various conditions are expressed by the following definition:

$$
\begin{aligned}
\operatorname{stab} \_t o t(Y, X) \equiv & \equiv_{\operatorname{def}}[\operatorname{stabilise}(Y, X) \wedge \forall Z[[\operatorname{cont}(\operatorname{sref}(Z), \operatorname{sref}(X)) \wedge \\
& \text { stabilise } \left.\left.(Z, X) \wedge \neg O(\operatorname{sref}(Z), \operatorname{sref}(Y)] \Rightarrow \operatorname{stab} \_t o t(Y, Z)\right]\right] .
\end{aligned}
$$

All these geometrical and functional tools enable us to state the following definition of the surl configuration:

$$
\begin{gathered}
\operatorname{sur} 1(\mathrm{X}, \mathrm{Y}) \equiv_{\operatorname{def}} \operatorname{catcomp} 1(\mathrm{X}, \mathrm{Y}) \wedge \operatorname{cont} 1(\operatorname{sref}(\mathrm{X}), \operatorname{sref}(\mathrm{Y})) \wedge \\
\operatorname{stabilise}(\mathrm{Y}, \mathrm{X}) .
\end{gathered}
$$

This definition shows that if $\mathrm{X}$ and $\mathrm{Y}$ have comparable categories, if the contact area of $\mathrm{X}$ (with $\mathrm{Y}$ ) is higher than the contact area of $\mathrm{Y}$ (with $\mathrm{X}$ ), and furthermore if $\mathrm{Y}$ stabilizes $\mathrm{X}$, we can then deduce that $X$ est sur $Y$ ' $\mathrm{X}$ is on $Y^{\prime}$. This is the case of a person sitting on a chair or a glass standing on a table.

The configuration sur 2 'on2' where the trajector is on the same level as the landmark, is represented by a similar definition, the only differences to be 
found in the kind of contact (cont2), in comparable categories (catcomp2) and in stabilization, which, in this case must be total:

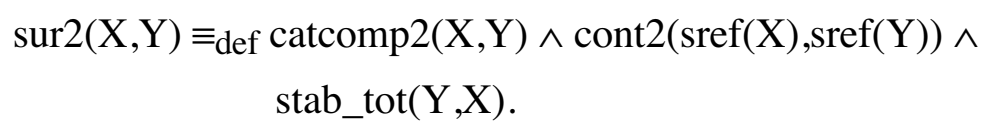

It must be reminded here that a total stabilization of $\mathrm{X}$ by $\mathrm{Y}$ implies that every entity $\mathrm{Z}$ disjoint from $\mathrm{Y}$ and directly stabilizing $\mathrm{X}$ is itself stabilized by Y. This way, a TV set on a shelf which is fixed on a wall can be said to be on the wall. On the other hand, if the shelf has legs and is resting (at least partially) on the floor, the wall does not act as a total stabilizer (of the TV) and the TV can only be described as being on the shelf (the shelf being against the wall).

The definition associated with the sur3 'on3' configuration differs from that associated with sur2 'on2' in the kind of contact between the entities involved and in the predicate catcomp3 (which is the most restrictive of the various "catcomp" predicates, particularly along the vertical axis):

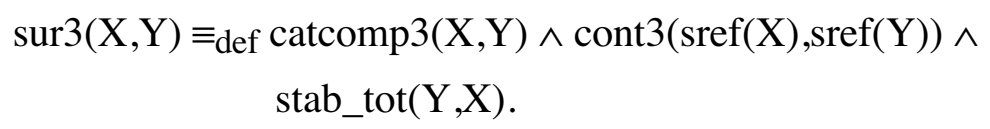

\subsubsection{The preposition dans}

The preposition dans 'in', used in the given syntactic structure and in a concrete spatial sense, can refer to three different configurations between trajector and landmark.

In the first configuration, probably the main case, dans links a trajector which is completely included in the interior of the landmark, as in the following examples. These cases are called "total dans".

(10) a. L'eau est dans le verre

'The water is in the glass'

b. La ville est dans le brouillard

'The city is in the fog'

c. Paul est dans l'île

'Paul is in the island'

d. Il y a un trou dans ce morceau de fromage

'There is a hole in this piece of cheese'

e. L'île est dans la mer

'The island is in the sea' 
In the second one, the trajector is only partially included in the interior of the landmark. We refer to these cases as "partial dans".

(11) a. La rose est dans le vase

'The rose is in the vase'

b. L'arbre est dans une petite cour

'The tree is in a small yard'

Finally, dans can be used to describe cases of meronomy; the trajector is then a part of the landmark. These cases are called "dans part-of".

(12) a. Mon cerveau est dans ma tête

'My brain is in my head'

b. La Bretagne est en France

'Brittany is in France'

c. Paul est dans le jury

'Paul is in the jury'

\section{a- "total dans", "partial dans" and the "interior" function}

The first two configurations involve the notion of interior in addition to geometrical relations (inclusion and overlap).

The interior of an entity must be distinguished: the entity and its interior must not be considered as a whole, since we want to differentiate between "total dans" and "dans part-of". It is worth noting that the interior, being a space portion, behaves in a very different way from the object: an object included in the interior is not a part of this interior since it can be removed without altering the interior's identity and shape, whereas a (connected) object included in another is a part of it, fully contributing to its nature. However, the interior of an entity is completely determined by this entity, and we always perceive one with the other. This fact has led many authors (including us in an earlier work (Borillo - Vieu 1989)) to consider the interior as being a part of the entity and then to formalize dans or in as the mere inclusion or overlap between the spatial referents of the trajector and the landmark.

The interior of an object can be of two types, depending on its ability to contain another object.

If the object is a "container" (solid, offering resistance to gravity and lateral movements $)^{19}$, then its interior is defined by functional properties, in

M. Aurnague - L. Vieu 
addition to geometrical ones. Otherwise, the interior can only be defined geometrically. The sentences (10a) and (11a) are examples of the "container" case. As Herskovits and Vandeloise have shown, the "place" of the interior of the glass (the space taken by the interior) cannot be defined only by removing the "place" of the glass in the convex hull of the "place" of the glass, which is a geometrical function. Indeed, we have already seen in the second section the situation of a fly and a glass that illustrates it (Figure 1). Restricting the scope of the convex hull to the containing parts of the object (as Vandeloise does) is not satisfactory either because in Figure 1, the fly would remain in the glass. We need to take each of the object's concavities into account and either "close" it or not, depending on its containing capability.

In the second case, the object is not a "container"; this occurs with collections: la foule 'the crowd', with non-solid objects: l'eau 'water', le brouillard 'fog' as in (10b), and with solid objects occupying a volume evenly without filling it: l'arbre 'the tree' (as in l'oiseau est dans l'arbre 'the bird is in the tree'). In these cases, the spatial referent of the interior is determined by an "outline" function. It should be noted that here too, this function is not simply the convex hull. To begin with, the outline clings closer to the sides of the object than the convex hull does. What is more, a sizeable "hole" may be excluded; for instance, if a crowd forms a circle, what is situated dans le cercle 'in the circle' is not situated dans la foule 'in the crowd', i.e. the interior of this circle is not a part of the interior of the crowd. ${ }^{20}$ There are also a few cases where the landmark is not a container, yet it is solid and it is not a collection. For instance, in la boite est dans le papier-cadeau 'the box is in the wrapping paper', the paper is not a container but is actually supported by the box. In these cases, the landmark completely surrounds its interior: the spatial referent of the interior is a connected part of the complement of the spatial referent of the landmark.

The interior of an object is used to locate other objects as in sentences (10a), (10b) and (11a). It is also used to locate space portions as in (10d). The interpretation of such a sentence is that the space portion (here the hole) is a part of the interior of the object (here the piece of cheese), the meronomy being a "piece-whole" case. It is not just an inclusion, for the hole is "attached" to the object just as the interior is, i.e. both are determined by the object. 
The interior of a location, as expressed in sentences (10c) and (11b), is determined by the location's boundaries and the vertical axis: it is the space portion situated above the ground portion considered. But its exact thickness is not determined. We cannot go too high: a plane flying over a town is not situated dans la ville 'in the town'. We cannot stay too low: a bird can be flying dans la plaine 'in the plain'. When the same noun phrase describes both an object and a location (a town, a forest...) the interior of the location includes the interior of the object.

It should be clear by now that the "interior" function does not embody a unique concept. However, we will not represent it in such detail because our perspective is not to generate discourses from perception and world knowledge, e.g. to decide what is the interior of a given object. Rather, we need to understand how the function interior behaves deductively. For this purpose, examining in detail what is conceived as an interior was helpful. We were led to the conclusion that for a first step, considering the interior as a whole was possible, as its deductive behaviour is almost homogeneous. We must admit that we are leaving some cases aside ${ }^{21}$, but we hope that in the future we can model the various notions of interior more precisely.

In addition to such cases, there are occurrences of "total dans" or "partial dans" that do not call for the use of an interior. The localization of an object in a space portion (e.g. la chouette est dans le creux de l'arbre 'the owl is in the tree's hollow') is just explained by the inclusion ("total dans") or overlap ("partial dans") of the object's spatial referent with the space portion's spatial referent. The localization of a location in another location, without any part-whole relation between the two is slightly more complicated. Sentence (10e) is an example of such localization; Berlin-ouest était en RDA 'West-Berlin was in DDR' is another one. In these (few) cases, the landmark totally and tightly surrounds the trajector. Another type of location's interior for situating locations could be defined, but its interest would be limited because not every location situated in such an interior would be dans the first location. For instance, a field in the island is not in the sea. A location is "total dans" ("partial dans" is not possible) another location if all the boundaries of the trajector are also boundaries of the landmark. 
An important fact to note is that even though it is impossible to deal with the function "interior" on the geometrical level (containment and classification of entities are involved in its definition), the preposition dans cannot be reduced to the relation of containment. There are many examples without any containment between the landmark and the trajector: in la mouche est dans la volière 'the fly is in the aviary', the cage does not prevent the fly from getting out of it, in any direction whatsoever; in (10b), the city is unable to move anyway, but the fog does not even support it.

The definition obtained for "total dans" is:

$$
\begin{aligned}
& \operatorname{dst}(X, Y) \equiv \operatorname{def}((\operatorname{obj}(X) \wedge(\operatorname{obj}(Y) \vee \operatorname{loc}(Y)) \wedge p(i(\operatorname{sref}(X)), \operatorname{sref}(\operatorname{int}(y)))) \\
& \vee(\operatorname{sp}-\operatorname{port}(X) \wedge \operatorname{obj}(Y) \wedge(\operatorname{mor}-\operatorname{tt}(X, \operatorname{int}(\mathrm{Y})) \vee \mathrm{X}=\operatorname{int}(\mathrm{Y}))) \\
& \vee(\operatorname{obj}(\mathrm{X}) \wedge \operatorname{sp}-\operatorname{port}(\mathrm{Y}) \wedge \mathrm{p}(\mathrm{i}(\operatorname{sref}(\mathrm{X})), \operatorname{sref}(\mathrm{Y}))) \\
& \vee(\operatorname{loc}(\mathrm{X}) \wedge \operatorname{loc}(\mathrm{Y}) \wedge \operatorname{front}(\Gamma, \operatorname{sref}(\mathrm{X}), \operatorname{sref}(\mathrm{Y})) \wedge \\
&\quad \operatorname{front}(\Gamma, \operatorname{sref}(\mathrm{X}), \mathrm{c}(\operatorname{sref}(\operatorname{ground})-\operatorname{sref}(\mathrm{X})))))
\end{aligned}
$$

The definition for "partial dans" is:

$$
\begin{gathered}
\operatorname{dsp}(\mathrm{X}, \mathrm{Y}) \equiv_{\operatorname{def}}((\operatorname{obj}(\mathrm{X}) \wedge(\operatorname{obj}(\mathrm{Y}) \vee \operatorname{loc}(\mathrm{Y})) \wedge \mathrm{o}(\mathrm{i}(\operatorname{sref}(\mathrm{X})), \operatorname{sref}(\operatorname{int}(\mathrm{y})))) \\
\vee(\operatorname{obj}(\mathrm{X}) \wedge \operatorname{sp}-\operatorname{port}(\mathrm{Y}) \wedge \mathrm{o}(\mathrm{i}(\operatorname{sref}(\mathrm{X})), \operatorname{sref}(\mathrm{Y})))
\end{gathered}
$$

These definitions are accompanied by the following postulates describing the function "interior":

- $\forall \mathrm{X} \forall \mathrm{Y}(\mathrm{Y}=\operatorname{int}(\mathrm{X})=>((\operatorname{obj}(\mathrm{X}) \vee \operatorname{loc}(\mathrm{X})) \wedge \operatorname{sp}-\operatorname{port}(\mathrm{Y}) \wedge \operatorname{det}(\mathrm{X}, \mathrm{Y}) \wedge$

$$
\forall \mathrm{Z}(\mathrm{Z}=\operatorname{int}(\mathrm{X})=>\mathrm{Y}=\mathrm{Z}) \wedge \operatorname{dc}(\operatorname{sref}(\mathrm{X}), \operatorname{sref}(\mathrm{Y}))
$$

$\wedge$

$$
\begin{gathered}
(\operatorname{obj}(\mathrm{X})=>\mathrm{p}(\mathrm{i}(\operatorname{sref}(\mathrm{Y})), \operatorname{preint}(\operatorname{sref}(\mathrm{X})))))) \\
\text { - } \forall \mathrm{X} \forall \mathrm{Y} \forall \mathrm{T} \forall \mathrm{U} \forall \mathrm{R}((\mathrm{T}=\operatorname{int}(\mathrm{X}) \wedge \mathrm{U}=\operatorname{int}(\mathrm{Y}) \wedge \operatorname{part}(\mathrm{X}, \mathrm{Y}) \wedge \\
\operatorname{rest}(\mathrm{Y}, \mathrm{X}, \mathrm{R}))=>\mathrm{p}(\operatorname{sref}(\mathrm{T}), \operatorname{sref}(\mathrm{U})+\operatorname{sref}(\mathrm{R}))) \\
\cdot \forall \mathrm{X} \forall \mathrm{Y} \forall \mathrm{T} \forall \mathrm{U} \forall \mathrm{R}((\mathrm{T}=\operatorname{int}(\mathrm{X}) \wedge \mathrm{U}=\operatorname{int}(\mathrm{Y}) \wedge \mathrm{p}(\mathrm{i}(\operatorname{sref}(\mathrm{X})), \operatorname{sref}(\mathrm{U})) \\
=>\mathrm{p}(\operatorname{sref}(\mathrm{T}), \operatorname{sref}(\mathrm{U})+\operatorname{sref}(\mathrm{Y})))
\end{gathered}
$$

With the geometrical function "preint" designating the convex hull of an individual minus this individual, and the relation $\operatorname{rest}(\mathrm{Y}, \mathrm{X}, \mathrm{R})$ expressing that $\mathrm{R}$ is the rest of the whole, $\mathrm{Y}$, once its part, $\mathrm{X}$, has been taken out.

\section{b- "dans part-of"}

The preposition dans cannot be used to describe any meronomy. Vandeloise showed that we cannot say *mon nez est dans ma tête 'my nose is in my head'. We think that this fact is better accounted for by a "contrast principle"

M. Aurnague - L. Vieu 
than by the explanation he gives (the trajector and the landmark should not share any boundary).

This principle expresses that when someone uses a spatial expression to describe a meronomy, he (as well as the hearer) conceives the part as detached from the whole and situates this part with respect to the rest of its whole. In the case of sentence (12a), we can see that detaching the brain from the head creates an interior where we situate the brain. Detaching the nose from the head does not create such an interior: the nose cannot be in the head. With this principle, we can even explain why in sentences like l'escargot / la noix est dans sa coquille 'the snail / the nut is in its shell', the whole is described as being in one of its parts! Note that only "total dans" is then possible between the part and the rest of the whole. The same principle can be found in many sentences corresponding to the syntactic structure Ntraj est sur ILN de Nland, such as la poignée est sur le devant de l'armoire 'the handle is on the front of the cupboard'. The relation être sur (here, "sur2") really links the handle and the front of the cupboard without its handle.

However, this principle is only required for a "dans part-of" describing

the meronomies "component-assembly" and "piece-whole", and only between objects. In all other cases every occurrence of a meronomy can be described by the preposition dans (as in sentence (12b)).

The definition of "dans part-of" is then:

$$
\begin{gathered}
\operatorname{dpt}(X, Y) \equiv_{\operatorname{def}} \operatorname{part}(X, Y) \wedge((\operatorname{obj}(X) \wedge(\operatorname{comp}-\operatorname{ass}(X, Y) \vee \operatorname{mor}-\operatorname{tt}(X, Y))) \\
=>\exists Z(\operatorname{rest}(Y, X, Z) \wedge \operatorname{dst}(X, Z)))
\end{gathered}
$$

\subsection{Validation: adequate inferences}

In the introduction, we presented our methodology: we wished to obtain a semantics allowing the same deductions as those accepted by human beings. The validation phase, i.e. the control of the adequacy between the two kinds of inferences, can now be done. We verify here the inferences a definition leads to by itself as well as some of the inferences obtained by combining the definitions of several markers or cases of the same marker.

\subsubsection{Transitivity of the meronomies}

We have distinguished several meronomies on the grounds that we felt they were describing different situations. It is important to verify that these

M. Aurnague - L. Vieu 
meronomies are really different in our system, i.e. that they behave in a different way. The part-whole relation has classically been taken as a unique relation and its transitivity assumed. But this has been proved wrong in (Winston - Chaffin - Herrmann 1987).

The relation "member-collection" is not transitive in our system, and it is consistent with its behaviour in NL as we have already seen:

Le Texas fait partie des USA and Les USA font partie de l'ONU $\neq>$ 'Texas is part of the USA' 'The USA are part of UNO'

* Le Texas fait partie de l'ONU

*'Texas is part of UNO'

This relation can be combined with the relation "subcollectioncollection":

$\forall \mathrm{X} \forall \mathrm{Y} \forall \mathrm{Z}((\mathrm{el}-\operatorname{coll}(\mathrm{X}, \mathrm{Y}) \wedge \operatorname{scoll}-\operatorname{coll}(\mathrm{Y}, \mathrm{Z})) \Rightarrow \mathrm{el}-\operatorname{coll}(\mathrm{X}, \mathrm{Z}))$

This is verified in NL. For instance, we have:

La Belgique fait partie du Benelux and Le Benelux fait partie de la CEE $\Rightarrow$

'Belgium is part of Benelux' $\quad$ 'Benelux is part of the EEC'

La Belgique fait partie de la CEE

'Belgium is part of the EEC'

The relation "subcollection-collection" is itself transitive, as are the relations "component-assembly" and "piece-whole". We can even combine the relations "piece-whole" and "component-assembly" (in this order only), the result being another relation "piece-whole". But not every mixed combination is valid. As shown by Winston, Chaffin \& Herrmann, we cannot mix "component-assembly" and "member-collection". This is also the case in the system:

Le bras de Jean fait partie de Jean and Jean fait partie du jury $\quad \neq>$

'John's arm is part of John' 'John is a member of the jury'

* Le bras de Jean fait partie du jury

*'John's arm is part of the jury'

Note that in this case, we do not even have a "component-assembly" or "piece-whole" relation between John's arm and the jury, since the jury is a collective entity.

The study of the various combinations and their validity can be found in (Vieu 1991: 293-296). 


\subsubsection{The ILNs and sur}

The definitions given for several ILNs and for the preposition sur 'on' under the constraints of "instantaneousness" and "unique speaker", result in the two following inferences:

- $\forall \mathrm{X} \forall \mathrm{Y} \forall \mathrm{Z} \forall \mathrm{N}((\operatorname{dessus}(\mathrm{Z}, \mathrm{Y}, \mathrm{N}) \wedge \operatorname{sur} 1(\mathrm{X}, \mathrm{Z}))=>$

$$
\exists \mathrm{U}(\operatorname{haut}(\mathrm{U}, \mathrm{Y}, \mathrm{N}) \wedge \operatorname{sur} 1(\mathrm{X}, \mathrm{U})))
$$

For instance, as common sense requires:

La boîte est sur le dessus de l'armoire

'The box is on the top extremity of the cupboard' =>

La boîte est sur le haut de l'armoire

'The box is on the top of the cupboard'

- $\forall \mathrm{X} \forall \mathrm{Y} \forall \mathrm{Z} \forall \mathrm{U} \forall \mathrm{N}((\operatorname{devant}(\mathrm{Z}, \mathrm{Y}, \mathrm{N}) \wedge \operatorname{sur} 2(\mathrm{X}, \mathrm{Z}) \wedge$

$$
\text { derrière }(\mathrm{U}, \mathrm{Y}, \mathrm{N}))=>\neg \operatorname{sur} 2(\mathrm{X}, \mathrm{U}))
$$

For instance:

L'étiquette est sur le devant de la boîte

'The label is on the front (extremity) of the box'=>

L'étiquette n'est pas sur le derrière de la boîte

'The label is not on the back (extremity) of the box'

The demonstrations of these theorems, along with several others of the same type are rather complex, in particular due to the comparison of contact areas in the semantics of sur. They are fully described in (Aurnague 1991: 247-259).

\subsubsection{The transitivities of dans}

First of all, studying the transitivities of dans shows that it was necessary to distinguish three cases: "total dans" is (in some cases) transitive, "partial dans" is not and the transitivity of "dans part-of" depends on the transitivity of the underlying meronomies. For instance:

- "total dans" is transitive (between two objects and a location):

Paul est dans la maison and La maison est dans l'île $\quad \Rightarrow$ 'Paul is in the house' 'The house is in the island'

\section{Paul est dans l'île}

'Paul is in the island' 
- "partial dans" is not transitive; moreover, the combination of a "total dans" and a "partial dans" is not valid:

L'abeille est dans la rose and La rose est dans le vase $\quad \neq>$

'The bee is in the rose' 'The rose is in the vase'

*L'abeille est dans le vase

*'The bee is in the vase'

Apart from the distinction in three cases, we have taken into account the class of each argument in the definitions of dans. This was important, as the transitivity of "total dans" depends on its arguments belonging to one or another class.

The combination of a "total dans" between an object and a location with a "total dans" between two locations is not valid:

Paul est dans l'ile and L'île est dans la mer $\quad \neq>$
'Paul is in the island'
'The island is in the sea'

*Paul est dans la mer

*'Paul is in the sea'

The combination of a "total dans" between a space portion and an object with a "total dans" between two objects is not valid, due to the presence of a meronomy ("piece-whole") in the first relation:

Il y a un trou dans le drap and le drap est dans le tiroir $\quad \neq>$

'There is a hole in the sheet' 'The sheet is in the drawer'

*Il y a un trou dans le tiroir

*'There is a hole in the drawer'

The complete study of all the possible combinations (about thirty) can be found in (Vieu 1991: 307-313), along with the study of combinations between dans and meronomies (not only those expressed by dans). As it has just been seen, there are many combinations which are not valid, even though many authors have until now taken the transitivity of dans (or in) for granted, defining it only by the relation of inclusion.

\section{The pragmatic level}

We have just seen that the adequacy was rather good between what the system is able to infer, and the deductions a human can make. However, this

M. Aurnague - L. Vieu 
adequacy is not perfect, because up to now we have only taken into account the semantic aspects of the spatial expressions and, as seen in section 2, pragmatic phenomena have quite an important influence on their meaning.

\subsection{Restrictions on inferences and additional information}

For instance, let us go back to example (6) from section 2. The system (made up of the geometrical and functional levels) states that the car's engine is in the garage, whereas a human would not. Therefore, we have to introduce in the system the underlying pragmatic principles people use, in order to filter out the relations inferred "wrongly" (they are not wrong but cannot be said). At the same time, the same principles can be used to deduce (by implicatures) more information than there actually is in the discourse.

We will now explore the pragmatic principles involved in the meaning of spatial expressions, although we do not claim to be exhaustive. These principles are not really formalized here, as this part of the work is not completed at the moment.

\subsubsection{The "fixation principle"}

This principle, first introduced in (Vandeloise 1986), expresses that the typical use of an object "fixes" some of its characteristics. For instance, the front and the back of a car are "fixed" by the usual direction of its motion: the front of the car remains the same even when the car is going backwards. We have seen in section 4.1 that many intrinsic orientations are determined in this way.

This principle is also at work when talking about the interior of an object. The interior of a bottle stays the same even when the bottle is handled upside down so that it cannot hold any liquid. Moreover, some of the containing concavities of an object can be rejected as part of its interior on the grounds that there exists another concavity which corresponds to the "fixed" interior. For instance, even if we accept sentence (13a) to describe the situation where an upside-down bottle has liquid which remains in the hollow of its underside, we will not accept (13b).

(13) a. Il y a de l'eau dans le dessous de la bouteille

'There is water in the underside of the bottle'

b. Il y a de l'eau dans la bouteille

'There is water in the bottle'

M. Aurnague - L. Vieu 
In fact, the inference from (13a) to (13b) is valid in the system since the interior of any part of an object is a part of the object's interior. Therefore, for the application of dans, we must check whether, in the world-knowledge base a "fixed" interior is specified for the landmark and whether the trajector is included in this fixed interior. However, nothing is certain here: a "marked" context may accept the use of (13b); that is why we could not take into account the "fixed" interiors earlier on the functional level. The same actually occurs for any phenomenon belonging to the pragmatic level: we can always find a particular context where the effects of a principle are contradicted.

Here is another (extreme) example of the effects of the fixation principle. The following transitivity, correct on the functional level, must be ruled out here:

Le crayon est dans la main and La main est dans le gant $=>$

'The pencil is in the hand' 'The hand is in the glove'

?Le crayon est dans le gant

?'The pencil is in the glove'

A phenomenon related to this principle must be mentioned. Some objects are not conceived as containers, so they are not usually used as a landmark for a dans expression. For instance, a table is not a container although it may have a drawer: the sentence the knife is in the table is difficult to accept in a non-marked context. Certain restrictions with some locations are also difficult to explain: one cannot say *dans la plage 'in the beach', *dans le terrain de football 'in the football field'...

All of the preceding concerned the restrictive aspect of the fixation principle. As a matter of fact, it can also generate some additional information. If sentence (13b) is present in the analysed discourse, we will have to assume, in the case of a "normal" context, that the water is in the fixed interior of the bottle. The same occurs for the sentence the pencil is in the glove, and indeed for many expressions, we even "choose" the most suitable part of the interior of an object: Mary is in the car strongly suggests that she is sitting in the passenger space and not in the boot. It must be reminded here that this kind of non-certain information has to be handled by a non-monotonic logic.

M. Aurnague - L. Vieu 


\subsubsection{The principle of maximum trajector}

This principle, a particular case of H.P. Grice's maxim of quantity (Grice 1975), has already been introduced in section 2 . The object localized by a spatial expression is usually the biggest object we can localize using the same expression. This principle must be used to restrict the results of the following inference rule, which is obviously true on the functional level:

$\forall X \forall Y \forall Z((\operatorname{dst}(X, Y) \wedge \operatorname{obj}(X) \wedge \operatorname{part}(Z, X))=>\operatorname{dst}(Z, Y))$

As we already said, the "principle of maximum trajector" can also be used to add information, stating that in a normal context, for every object localized by a spatial expression, any object it is a part of is not localized the same way.

A word must be said about the application of this principle to spatial expressions involving a "partial dans". In fact, the contrary should almost be stated, since the relevance of these expressions decreases as the portion of the trajector totally included in the landmark gets smaller (in proportion). Several rules governing the acceptability of a "partial dans" must be taken into account, since, on the functional level, any partial inclusion between an object and the interior of another is described as a "partial dans". One of these rules states that if there is a typical function between two objects, the object that is situated in the other being also a part of a third one, we cannot express that this third object is "partial dans" the second. For instance, le doigt est dans le $d e ́$ 'the finger is in the thimble' implies on the functional level, la main est dans le dé 'the hand is in the thimble', which is clearly not acceptable and discarded by this rule.

We can then see that the pragmatic level has to apply several rules, which are contradictory in some situations. For the moment, it is quite difficult to establish priorities; as said before, the pragmatic level is still in the process of being studied.

\subsubsection{The principle of minimum landmark}

As the general purpose of a spatial expression is to help the hearer in finding the object localized by the expression, the maxim of quantity requires the use of the best localizing landmark. We could conclude that the smaller the landmark, the easier the finding (the hearer knowing where it is). For instance, if Peter has a key in his pocket and Peter is in the kitchen, it is clear 
that the key is in Peter's pocket is much better than the key is in the kitchen. ${ }^{22}$ This principle would actually suggest that modelling any kind of transitivity is helpless.

What really occurs here is that the last sentence is misleading because Peter (then, Peter's pocket) is not more likely to be in the kitchen than in another room, and someone looking for the key in the kitchen would not think about looking in Peter's pocket. It must be noticed that, if instead of Peter's pocket, the key was in a drawer or a dish, or anything that does not move around by itself, the key is in the kitchen would be totally acceptable.

Moreover, such a principle is not desirable because there are some cases where the position of the smallest landmark is determined by the trajector itself. For instance, the gift is in the wrapping paper is not a "good" sentence to help locate the gift.

So, this principle is not exactly what is needed here, although we must admit that, in general, if the system is to answer a question like where is $X$ ?, it should give the smallest known location. We can then see that Grice's maxims cannot directly be applied. Each of them must be examined for the particular domain of spatial expressions.

\subsubsection{Relevance}

Relevance is a vague concept, which could also cover the preceding principles. We want to consider several phenomena governing the acceptability of a spatial relation describing a situation with respect to another relation (up to now, the principles described were about the choice of the arguments of a given relation, not the relation itself).

Several relations may compete. For instance, in the case of a bowl turned upside down over an apple, the prepositions dans 'in' and sous 'under' could both describe the situation. However, sous is chosen because the apple and the bowl are not in the situation typically described when using dans, one in which the bowl contains the apple. Containment is not a necessary condition for the use of dans, but it obviously makes it more relevant. Similarly, one is likely to assume that the sentence la pomme est dans le bol 'the apple is in the bowl' describes a situation where the bowl contains the apple. However, containment is not assumed when the typical situation does not involve containment: la main est dans le gant does not suggest that the glove controls the hand's movements. Here again, we need

M. Aurnague - L. Vieu 
world knowledge about typical situations. It must be noted that typicality and relevance are both concepts that rely heavily on the function of the objects: the function of a bowl is to contain, whereas the function of a glove is to surround a hand in order to protect it. Therefore, the existence of the functional level is crucial for the pragmatic one.

\subsection{Additional inferences}

A spatial expression can be used to describe a situation where in fact its semantics is not totally verified. For instance, a book is usually said to be "on the table" even though the book is on another book, thus not in contact with the table. The loosened definition of "sur1", by dropping the contact, gives rise to a kind of "inference", namely the transitivity of "sur1".

These inferences are not real ones and could not be included on the functional level. Because the relation between the two books is not relevant, one can "forget" about it and put the top book directly in relation to the table. A. Herskovits shows in (Herskovits 1982) that, if instead of two books one on top of the other, it was a lid on a tea-pot, it would be impossible to "infer" that the lid is on the table. In this case, being on the tea-pot, the lid fulfils its function with respect to the tea-pot, so it is relevant for a lid to be on a teapot. Consequently, this fact cannot be "forgotten". The underlying pragmatic principles involved in this example are the maxims of relevance and of quantity. If a fact is relevant (in this case the lid is on the pot), to express a less precise fact (in this case the lid is on the table) somehow implies that the precise fact is not verified in the given situation.

We must mention that it was impossible to deal similarly with "partial dans", that is considering that loosening an inclusion into an overlap is a pragmatic phenomenon, because a "partial dans" is not always used to focus on the part of the trajector which is entirely contained in the landmark. For instance, in la rose est dans le vase 'the rose is in the vase', the part of the rose which is out of the vase cannot be "forgotten" for it is the main part of it!

Even though the separation of pragmatics from semantics is not universally agreed on, we hope to have shown how and why separation is needed in our system. We are convinced that without getting into such detail, it would be almost impossible to formalize the meaning of spatial expressions, i.e. to model the deductions allowed by common sense.

M. Aurnague - L. Vieu 


\section{Conclusion}

Formal semantics of NL expressions referring to space must integrate the different aspects which underlie their semantics. As shown with the analysis of dans 'in' and sur 'on', mere geometrical data is insufficient to express the semantics of such lexemes, and functional or pragmatic aspects must be also taken into account. These observations have led us to build a three-level system (geometrical, functional and pragmatic) with which we can represent the meaning of spatial expressions and make deductions. This modular construction thus permits us to come closer to the natural reasoning expressed in the discourse and, from this point of view, constitutes a real cognitive approach. Beyond simple comparison between deductions made and reasoning of the speaker, we contemplate now validating our system (in collaboration with psychologists) by verifying through various experiments the psycholinguistic anchorage of the concepts and primitives introduced (Borillo, M. 1991). It must be stressed that the class of lexemes for which we gave a formal definition (namely the prepositions dans 'in' and sur 'on' and ten ILNs) seems to be wide enough to encompass the principal concepts underlying the expression of space in NL. Consequently, we think that the semantic content of most spatial expressions can be represented within the framework of this three-level system, perhaps with modifications or additions. Another interest of this modular approach lies in the fact that the geometrical module which is specially suited to NL processing is really independent of it because the individuals handled there have only spatiotemporal properties. The characteristics of this geometrical structure make it very useful for other fields of Artificial Intelligence than NL. Indeed, a similar approach is used in (Randell - Cohn 1989) to model naive physics processes such as phagocytosis and the behaviour of a "force pump".

Finally we hope that this research lays the foundations of a methodology for a formal semantics of space.

\section{Acknowledgements}

The authors would like to thank Mario Borillo for his continuing guidance. They are also very grateful to Andrée Borillo for her judicious advice. This work was carried out at IRIT, within the framework of two Ph.D. theses, under the direction of Mario Borillo. 


\section{Notes}

Here we are in opposition to Vandeloise's position who takes an allfunctional point of view. But looking closer at his proposition, purely geometrical aspects are included in the description of some of his "family resemblances".

2 By particular cases, we mean the different definitions given for each expression in section 4. For instance, "total dans", "partial dans" or "dans/part-of" for the expression "Ntraj être dans Nland".

Mereology was introduced by S. Lesniewski (Lesniewski 1927-1931) and taken up by various researchers among whom H. Leonard \& N. Goodman. However, people often directly refer to (Leonard - Goodman 1940), probably for reasons of accessibility and readability.

It must be noted that it is not possible to define the closure of the universal individual $\mathrm{a}^{*}$, because the complement of $\mathrm{a}^{*}$, which should be the null element, does not exist in this theory.

5 Associating a system of three orthogonal axes to a sphere reveals its threedimensional nature and means that, interacting with it, a person can define a threedimensional system. However, because of the regularity of its shape, the exact position of the system of axes with respect to this sphere cannot be determined

6 An entity $\mathrm{X}$ immediately contains an entity $\mathrm{Y}$ if $\mathrm{pp}(\operatorname{sref}(\mathrm{Y}), \operatorname{sref}(\mathrm{X}))$ and there is no $\mathrm{Z}$ such that $\mathrm{pp}(\operatorname{sref}(\mathrm{Y}), \operatorname{sref}(\mathrm{Z}))$ and $\mathrm{pp}(\operatorname{sref}(\mathrm{Z}), \operatorname{sref}(\mathrm{X}))$.

7 As we already said, part-whole relations cannot be reduced to the spatial inclusion and require various functional notions to be taken into account. We will explain further (in section 4.2.2) how we define, on the functional level, various categories of partwhole relations that allow us, for example, to distinguish functionally and geometrically well "delimited" components of an entity (comp-ass $(\mathrm{X}, \mathrm{Y}))$ from arbitrary pieces of it (mor$\mathrm{tt}(\mathrm{X}, \mathrm{Y}))$. The relation $\operatorname{part}(\mathrm{X}, \mathrm{Y})$ covers all the cases.

In fact, another orientation predicate noted "orient 1 " exists in our system. It is intended to deal with the relations between abstract directions like those occurring between the systems of axes associated with the different parts of the same object. With this predicate, we can model the inheritance process of a deictic orientation between an object and one of its parts.

9 Consequently, the nature of the orientation denoted by the predicate natur_or((X,Axe,Dir),(A,D),V,N) can be computed by simply comparing the oriented entity $\mathrm{X}$ and the orientor entity $\mathrm{V}$ in the predicate orient.

M. Aurnague - L. Vieu 

object.

11 In this structure, it is then impossible to make the difference between a singleton and its unique member. We could not find any evidence of NL's behaving otherwise.

12 Only the join operator is useful with respect to mass term properties. This semi-lattice is non-atomic in G. Link's theory: he assumes that there are no minimum portions of a given substance.

13 To fully understand this logic, the reader is strongly invited to read (Link 1983). As for mass terms' behaviour, the reader may refer to (Pelletier - Schubert 1989), a good synthesis of the abundant literature on this topic.

14 This is not the case for any mass term. For example, it is impossible to determine what is an elementary particle of 'dirt', 'mud', 'milk shake'... However, the "set approach" has been taken by a number of authors such as Laycock (1972).

15 Actually, there are two more classes of entity: portions of matter and substances. They are needed to represent mass terms and the two meronomies we have set aside.

16 The space portions could be considered as being of the same type as spatial referents, that is, as being no entity, since their spatial referent as well as all of their properties derive from those of objects or locations. This position was not chosen because we can talk about space portions on the same level as for other entities, and we can even state some of their properties, e.g. the cave is dark and humid.

17 The position on the vertical axis of an element $\mathrm{X}$ with respect to an element $\mathrm{Y}$ is calculated by comparing the projection intervals of $\mathrm{X}$ and $\mathrm{Y}$ on an axis (Z,Axe) (of an entity Z) deictically oriented as a vertical axis.

18 With nouns referring to types of location like countries or regions, the use of dans is impossible and en 'in' has to be used (e.g. Paul est en France 'Paul is in France'). Because this fact cannot be explained on semantic grounds, we will deal with these cases as well.

19 This property is actually complex and goes deeply into several "clusters" of naive physics. For example, friction is involved in the situation of a bulb contained by a socket.

20. Here again, to be able to distinguish between several entities having the same spatial referent can be useful. Note that the circle is not linked to the plural entity which the crowd is linked to, so it is not a collection.

M. Aurnague - L. Vieu 
21 For instance, from la ville est dans l'enceinte 'the city is in the (surrounding) wall' and l'enceinte est dans les arbres 'the wall is in the trees', the sentence la ville est dans les arbres 'the city is in the trees' does not follow, and yet our model does infer this fact. The characterisation of an interior we give actually covers quite well all cases except the case of an "outline" function applied to a landmark having a "hole" (in this example, it is the case for the trees)

22 This example was provided by E. Audureau. 


\section{Bibliography}

Allen, James

1984 "Towards a general theory of action and time", Artificial Intelligence 23, 2: 123-154.

Aurnague, Michel

1991 Contribution à l'étude de la sémantique formelle de l'espace et $\mathrm{du}$ raisonnement spatial: la localisation interne en français, sémantique et structures inférentielles. [Unpublished Ph.D. dissertation, Toulouse: Université Paul Sabatier.]

Bach, Emmon

1986 "The algebra of events", Linguistics and Philosophy 9: 516.

Bäuerle, Rainer -- Urs Egli -- Arnim von Stechow (eds.)

1979 Semantics from different points of view. Berlin: Springer.

Bäuerle, Rainer -- Christopher Schwarze -- Arnim von Stechow (eds.)

1983 Meaning, use and interpretation of language. Berlin: de Gruyter.

Borillo, Andrée

1988 "Le lexique de l'espace: les noms et les adjectifs de localisation interne", Cahiers de Grammaire 13: 1-22, Toulouse: UTM.

Borillo, Mario

1991 "Sémantique de l'espace et raisonnement spatial", in: Proceedings of the Colloque Sciences de la Cognition. Paris: MRT.

Borillo, Mario -- Laure Vieu

1989 "Eléments pour la formalisation du raisonnement spatiotemporel naturel", in: Proceedings of the 7th Congrès RFIA. Paris: AFCET.

Bunt, Harry

1985 Mass terms and model-theoretic semantics. Cambridge: Cambridge University Press. 
Clarke, Bowman

1981 "A calculus of individuals based on "connection"", Notre

Dame Journal of Formal Logic 22, 3: 204-218.

Clarke, Bowman

1985 "Individuals and points", Notre Dame Journal of Formal Logic 26, 1: 61-75.

Cole, Peter -- Jerry Morgan (eds.)

1975 Syntax and Semantics 3: Speech Acts. New-York:

Academic Press.

Gabbay, Dov -- Franz Guenthner (eds.)

1989 Handbook of philosophical logic. Vol 4. Dordrecht: Reidel.

Grice, H.Paul

1975 "Logic and conversation", in: Cole -- Morgan (eds.), 4158.

Hayes, Patrick

1985 "The second naive physics manifesto", in: Hobbs -- Moore (eds.), 1-36.

Herskovits, Annette

1982 Space and the prepositions in English: regularities and irregularities in a complex domain. Ph.D. dissertation, Stanford University.

1985 [published at Cambridge: Cambridge University Press.]

Hobbs, Jerry -- Robert Moore (eds.)

1985 Formal theories of the commonsense world. Norwood, NJ: Ablex.

Kamp, Hans

1979 "Events, instants and temporal reference", in: Bäuerle -Egli -- von Stechow (eds.), 376-417.

Lang, Ewald

1990 "Primary perceptual space and inherent proportion schema: two interacting categorization grids underlying the conceptualization of spatial objects", Journal of Semantics 7: $121-141$.

Laycock, Henry

1972 "Some questions of ontology", Philosophical review 81: 342.

M. Aurnague - L. Vieu 
Leech, Geoffrey

1969 Towards a semantic description of English. London: Longman.

Leonard, Henry -- Nelson Goodman

$1940 \quad$ "The calculus of individuals and its uses", The Journal of Symbolic Logic 2, 2: 45-55.

Lesniewski, Stanislaw

1927-1931 "O podstawach matematyki" [On the Foundations of Mathematics], Przeglad Filosoficzny [Philosophical Review] vols 30-34.

Link, Godehart

1983 "The logical analysis of plurals and mass terms: A lattice theoretical approach", in: Bäuerle -- Schwarze -- von Stechow (eds.).

Miller, Georges -- Phillip Johnson-Laird

1976 Language and perception. Cambridge, MA: Belknap Press of Harvard University Press.

Pelletier, Francis -- Lenhart Schubert

1989 "Mass expressions", in: Gabbay -- Guenthner (eds.), $327-$ 407.

Pick, Herbert -- Linda Acredolo (eds.)

1983 Spatial orientation: theory, research and application. NewYork: Plenum.

Quine, Willard

$1960 \quad$ Word and object. Cambridge, MA: MIT Press.

Randell, David -- Anthony Cohn

1989 "Modelling topological and metrical properties in physical processes", in: Brachman -- Lesveque -- Reiter (eds.), Proceedings of KR'89, 357-368.

Talmy, Leonard

1983 "How language structures space", in: Pick -- Acredolo (eds.), 225-282.

Vandeloise, Claude

1986 L'espace en français: sémantique des prépositions spatiales.

Paris: Seuil - Travaux en Linguistique.

M. Aurnague - L. Vieu 
Vieu, Laure

1991 Sémantique des relations spatiales et inférences spatiotemporelles: une contribution à l'étude des structures formelles de l'espace en langage naturel. [Unpublished Ph.D. dissertation, Toulouse: Université Paul Sabatier.]

Whitehead, Alfred

1929 Process and reality. New-York: Mac Millan.

Winston, Morton -- Roger Chaffin -- Douglas Herrmann

1987 "A taxonomy of part-whole relations", Cognitive Science 11: 417-444. 